\title{
1 Mechanosensory trichome cells evoke a mechanical stimuli-induced 2 immune response in plants
}

4 Mamoru Matsumura ${ }^{1,10}$, Mika Nomoto ${ }^{1,2,10 *}$, Tomotaka Itaya ${ }^{1,2}$, Yuri Aratani ${ }^{3}$, Mizuki

5 Iwamoto $^{4}$, Takakazu Matsuura ${ }^{5}$, Yuki Hayashi ${ }^{1}$, Toshinori Kinoshita ${ }^{1,6}$, Izumi C Mori ${ }^{5}$,

6 Takamasa Suzuki $^{7}$, Shigeyuki Betsuyaku ${ }^{4,8}$, Steven H Spoel ${ }^{9}$, Masatsugu Toyota ${ }^{3}$, Yasuomi

$7 \quad \operatorname{Tada}^{1,2 *}$

$8{ }^{1}$ Division of Biological Science, Graduate School of Science, Nagoya University, Aichi, 9 Japan.

$10{ }^{2}$ Center for Gene Research, Nagoya University, Aichi, Japan.

$11{ }^{3}$ Department of Biochemistry and Molecular Biology, Saitama University, Saitama, Japan.

$12{ }^{4}$ Graduate School of Life and Environmental Sciences, University of Tsukuba, Ibaraki, Japan.

$13{ }^{5}$ Institute of Plant Science and Resources (IPSR), Okayama University, Okayama, Japan.

$14{ }^{6}$ Institute of Transformative Bio-Molecules (WPI-ITbM), Nagoya University, Aichi, Japan.

$15{ }^{7}$ Department of Biological Chemistry, College of Bioscience and Biotechnology, Chubu

16 University, Aich, Japan.

$17{ }^{8}$ Faculty of Life and Environmental Sciences Microbiology Research Center for

18 Sustainability, University of Tsukuba, Ibaraki, Japan.

$19{ }^{9}$ Institute of Molecular Plant Sciences, School of Biological Sciences, University of 20 Edinburgh, Edinburgh, UK.

$21{ }^{10}$ These authors contributed equally.

22 Lead contact

$23 *$ *Correspondence: nomoto@gene.nagoya-u.ac.jp (M.N.); ytada@gene.nagoya-u.ac.jp (Y.T.). 


\section{Abstract}

26 Perception of pathogen-derived ligands by corresponding host receptors is a pivotal strategy

27 in eukaryotic innate immunity. In plants, this is complemented by circadian anticipation of

28 infection timing, promoting basal resistance even in the absence of pathogen threat. Here, we

29 report that trichomes, hair-like structures on the epidermis, directly sense external

30 mechanical forces caused by raindrops to anticipate waterborne infections in Arabidopsis

31 thaliana. Exposure of leaf surfaces to mechanical stimuli initiates the concentric propagation

32 of intercellular calcium waves away from trichomes to induce defence-related genes.

33 Propagating calcium waves enable effective immunity against pathogenic microbes through

34 the calmodulin-binding transcription activator 3 (CAMTA3) and mitogen-activated protein

35 kinases. We propose a novel layer of plant immunity in which trichomes function as

36 mechanosensory cells to detect potential risks. 


\section{Introduction}

Innate immunity is an evolutionarily conserved front line of defence across the plant and animal kingdoms. In plants, pattern-recognition receptors (PRRs), such as leucine-rich repeat receptor-like kinases (LRR-RLKs) and LRR receptor proteins (LRR-RPs), specifically recognize microbe-associated molecular patterns (MAMPs) as non-self molecules, leading to the activation of pattern-triggered immunity (PTI) to limit pathogen proliferation ${ }^{1,2}$. While adapted pathogens have evolved virulence effectors that can circumvent PTI, plants also deploy disease resistance $(R)$ genes, primarily encoding nucleotide-binding LRR proteins, which mount effector-triggered immunity $(\mathrm{ETI})^{3-5}$. ETI often culminates in a hypersensitive response as well as acute and localized cell death induced at the site of infection and accompanied by profound transcriptional changes of defence-related genes to retard pathogen growth ${ }^{4,5}$. These ligand-receptor systems are largely dependent on a transient increase in intracellular calcium concentration $\left(\left[\mathrm{Ca}^{2+}\right]_{i}\right)$, followed by the initiation of phosphorylation-dependent signalling cascades, including mitogen-activated protein kinases (MAPKs) and calcium-dependent protein kinases, that orchestrate a complex transcriptional network and the activity of immune mediators ${ }^{6,7}$.

In addition to PTI and ETI, plant immunity can be induced periodically in the absence of pathogen threat, a process that is under the control of the circadian clock and driven by daily oscillations in humidity as well as light-dark cycles ${ }^{8-10}$. Such responses enable plants to prepare for the potential increased risk of infection at the time when microbes are anticipated to be most infectious. Therefore, the anticipation of potentially pathogenic microorganisms through sensing of climatological changes on the one hand and their specific detection on the other constitute two distinct layers of the plant immune system. 
Among the climatological factors that affect the outcome of plant-microbe interactions, rain is a major cause of devastating plant diseases, as fungal spores and bacteria are spread through rain-dispersed aerosols or ballistic particles splashed from neighbouring infected plants. In addition, raindrops contain plant pathogens, including Pseudomonas syringae and Xanthomonas campestris, and negatively regulate stomatal closure, which facilitates pathogen entry into leaf tissues ${ }^{11-13}$. High humidity, which is usually associated with rain, enhances the effects of bacterial pathogen effectors, such as HopM1, and establishes an aqueous apoplast for aggressive host colonization ${ }^{14}$. These findings suggest that it would be beneficial for plants to recognize rain as an early risk factor for infectious diseases.

How do plants respond to rain? Rain induces the expression of mechanosensitive TOUCH $(T C H)$ genes in plants $^{15}$. Mechanostimulation may affect a variety of plant physiological processes mediated by hormones such as auxin, ethylene, and gibberellin ${ }^{16-19}$. Arabidopsis thaliana seedlings exposed to rain-simulating water spray accumulate the immune phytohormone jasmonic acid (JA) to promote the expression of JA-responsive genes $^{20}$. Thus, rain modulates both mechanotransduction and hormone-signalling pathways that could affect the growth and development of plants as well as environmental responses. However, the regulatory mechanisms underpinning the rain-activated signalling pathway have not been fully elucidated.

Here, we report a novel layer of the plant immune system evoked by sensing mechanostimulation of falling raindrops: trichomes, hair-like cells on the leaf surface, function as mechanosensory cells that mount an effective immune response against both biotrophic and necrotrophic pathogens. When trichomes are mechanically stimulated, intercellular calcium waves are concentrically propagated away from them, and this is 
followed by the activation of MAPKs and initiation of the calcium- and calmodulin-binding transcription activator (CAMTA)-regulated immune response. We propose that plants directly recognize rain as a risk factor and evoke a rapid immune response that substantially contributes to early detection of, and protection from, potential pathogens.

\section{Results and discussion}

\section{Rain and mechanical stimuli induce mechanosensitive genes involved in plant immunity}

To investigate the effect of rain on transcriptional changes in Arabidopsis leaves, we performed transcriptome deep sequencing (RNA-seq) of wild-type Columbia (Col-0) Arabidopsis treated with artificial raindrops (Supplementary Fig. 1a; Methods). After applying only 10 falling droplets, we detected the marked induction of 1,050 genes 15 min after treatment (Supplementary Table 1). Gene Ontology (GO) analysis of these genes revealed a striking enrichment in categories associated with plant immunity, as evidenced by the expression of major immune regulators including WRKY DNA-BINDING PROTEIN (WRKY) genes, CALMODULIN BINDING PROTEIN 60-LIKE g (CBP60g), MYB DOMAIN PROTEIN (MYB) genes, ETHYLENE RESPONSE FACTOR (ERF) genes, and MAP KINASE $(M P K)$ genes $^{21,22}$ (Fig. 1a, Supplementary Table 1, Supplementary Table 2). The touchinduced genes $\mathrm{TCH} 2$ and $\mathrm{TCH} 4$ were also highly upregulated in response to one falling raindrop (falling) compared to a water droplet placed directly on the leaf surface (static) (Supplementary Fig. 1b). These results suggested that mechanosensation is involved in altering transcriptional activity.

To validate this hypothesis, we mechanically stimulated rosette leaves by gently brushing them one to ten times along the main veins with a small paint brush (Supplementary Fig. 1c; Methods) and analysed the expression profile of the immune regulator WRKY33, 
109 which was responsive to raindrops. WRKY33 expression was maximally induced 15 min after

110 brushing the leaves one to four times (Supplementary Fig. 1d). Next, we compared gene

111 expression patterns between leaves that were brushed once and those that received 10 falling

112 raindrops. Both raindrops and brushing strongly upregulated TCH2, TCH4, WRKY33,

113 WRKY40, WRKY53, CBP60g, MYB51, ERF1, and JASMONATE-ZIM-DOMAIN PROTEIN

$1141(J A Z 1)$ expression ${ }^{15,21,22}$ (Fig. 1b, c), suggesting that raindrops are likely recognized as a 115 mechanical stimulus.

116 Then, to comprehensively identify mechanosensitive genes, we performed an RNA117 seq analysis of leaves brushed once. We identified 1,241 genes that were significantly 118 induced 15 min after this treatment relative to control plants (Supplementary Table 3). These 119 mechanical stimuli (MS)-induced genes were primarily categorized as plant immune 120 responses, such as response to chitin, defence response, and immune system response (Fig.

121 1d, Supplementary Table 4). We found that $87.3 \%$ of raindrop-induced genes and $73.9 \%$ of 122 MS-induced genes overlapped (Fig. 1e): this set of 917 genes expressed upon both treatments 123 was enriched in GO categories associated with stress responses (Supplementary Fig. 1e). 124 Furthermore, the expression levels of these 917 genes, including major immune regulators, 125 were strongly positively correlated between the two treatments (Pearson correlation 126 coefficient $r=0.917$ ) (Fig. 1f). These transcriptome analyses indicated that falling raindrops 127 stimulate the expression of mechanosensitive genes involved in environmental stress 128 responses, including plant immunity.

130 Rain and MS rapidly activate plant immune responses

131 To further characterize raindrop-induced genes, we conducted a comparative analysis with 132 published transcriptome datasets. Many raindrop- and MS-induced genes were also 
133 expressed during major plant immune responses, such as those triggered by the immune 134 phytohormones salicylic acid (SA), which is effective against biotrophic pathogens (21\%; 135 193/917 genes), and JA, which mounts immune responses to necrotrophic pathogens (11.8\%;

136 108/917 genes); the bacterial-derived peptide flg22, which activates PTI (37\%; 339/917 137 genes); and the bacterial pathogen Pseudomonas syringae pathovar maculicola ES4326 (Psm 138 ES4326) $(25.8 \% ; 237 / 917 \text { genes) })^{1,2,23-25}$ (Fig. 2a, b). In total, 58.6\% (537/917 genes) of 139 raindrop- and MS-induced genes overlapped with those induced in response to different 140 immune elicitors, suggesting that raindrops activate mechanosensitive immune responses. Since stress-responsive gene expression is either positively or negatively regulated 142 by phytohormones, we determined the changes in the accumulation levels of six 143 phytohormones [SA, JA, JA-isoleucine (JA-Ile), abscisic acid (ABA), gibberellic acid 4 $144\left(\mathrm{GA}_{4}\right)$, and indole-3-acetic acid (IAA)] in leaves treated with 10 falling droplets and in those 145 brushed once. No significant changes in the levels of the phytohormones, except JA and JA146 Ile, were observed $5 \mathrm{~min}$ after treatment (Fig. 2c), consistent with the previous report that 147 water spray induces JA-mediated transcriptional changes ${ }^{20}$. The slight increase in JA and JA148 Ile could explain the observation that only $11.8 \%$ of raindrop- and MS-induced genes are JA149 responsive (Fig. 2a). Although 21\% of raindrop- and MS-induced genes overlap with SA150 responsive genes (Fig. 2a), SA levels were not significantly increased in response to 151 raindrops and MS (Fig. 2c). Therefore, most mechanosensitive genes, whose expression is 152 induced $5 \mathrm{~min}$ after treatment with raindrops, are presumably regulated independently of 153 phytohormonal responses. A previous report demonstrated that GA accumulation is reduced by "bending" leaves twice per day for 2 weeks ${ }^{19}$. Here, significant changes in GA levels were

155 not detected upon transient application of raindrops or MS (data not shown). These results 156 indicated that plants differentially respond to MS depending on their intensity and duration. 

immune responses. In particular, PRRs promptly activate a phosphorylation cascade involving MPK3 and MPK6 in response to MAMPs, whereby the downstream immune

160 components of PTI are phosphorylated to promote transcriptional reprogramming ${ }^{1,6,7,26}$.

161 Because $37 \%$ of raindrop- and MS-induced genes were also upregulated by flg22 treatment

162 (Fig. 2a), we examined whether a MAPK cascade is activated in responses to raindrops and 163 MS by immunoblot analysis with the anti-p44/p42 antibody, which detects phosphorylated $164 \mathrm{MPK} 3 / \mathrm{MPK}^{27,28}$. Upon treatment of rosette leaves with 4 falling raindrops or MS (1 165 brushing), phosphorylation of MPK3/MPK6 was induced within 3 min and remained high 166 for 10 min after each treatment (Fig. 2d, e), indicating that MPK3/MPK6 activation precedes 167 the expression of mechanosensitive genes detected 10 min after MS application 168 (Supplementary Fig. 1d). The kinetics of MS-activated MPK3/MPK6 were reminiscent of 169 those observed upon activation of the PRR protein FLS2 and its coreceptor BRI1170 ASSOCIATED RECEPTOR KINASE 1 (BAK1), which are responsible for recognition of 171 the bacterial flg22 epitope ${ }^{1,26}$. Wild-type, $f l s 2$, and bak1 mutant plants displayed comparable 172 levels of phosphorylated MPK3/MPK6 in response to MS (Fig. 2f), however, suggesting that 173 FLS2 and BAK1 are not positively involved in raindrop-elicited mechanotransduction. against published transcriptome datasets describing the specific and conditional activation of 176 MPK3/MPK6 in transgenic Arabidopsis plants carrying a constitutively active variant of 177 tobacco (Nicotiana tabacum) MAP KINASE Cab 2 (NtMEK2) under the control of the 178 dexamethasone-inducible promoter $^{28}$. Approximately 27.5\% (252/917 genes) of both 179 raindrop- and MS-induced genes were upregulated by MPK3/MPK6 ${ }^{28}$ (Supplementary Fig. 180 2a, Supplementary Table 5), and these upregulated genes were highly enriched in categories 
181 associated with plant immunity (Supplementary Fig. 2b, Supplementary Table 6), suggesting 182 that MAPKs play a critical role in mechanotransduction.

Rain and MS confer resistance to both biotrophic and necrotrophic pathogens

185 We then investigated whether raindrops and MS confer resistance to pathogenic microbes.

186 Raindrops containing the spores of the necrotrophic pathogen Alternaria brassicicola Ryo-1

187 were placed on fully expanded leaves after pretreatment with raindrops or MS for $3 \mathrm{~h}$ at an 188 interval of $15 \mathrm{~min}$. Both stimuli significantly suppressed lesion development compared to 189 control plants without pretreatment (Fig. 2g, h). Pretreatment of leaves with MS for $3 \mathrm{~h}$ also 190 efficiently protected plants from infection with the biotrophic pathogen Psm ES4326 (Fig. 191 2i). These results confirmed that mechanostimulation induces a PTI-like response to confer 192 a broad spectrum of resistance to both biotrophic and necrotrophic pathogens, as MS activate

193 immune MAPKs and upregulate a large subset of flg22-induced genes. In support of this 194 argument, exposure to the fungal cell wall, chitin, also upregulated 42.1\% (386/917 genes) 195 of raindrop-induced genes (Supplementary Fig. 2c).

197 Mechanosensitive genes are regulated by calmodulin-binding transcription activator 3

198 To dissect rain-induced mechanotransduction, we searched for a conserved cis-regulatory 199 element in the promoter sequences of mechanosensitive genes. From an unbiased promoter 200 analysis of the top 300 genes among 917 differentially expressed genes, we obtained the 201 highest enrichment for the CGCG box (CGCGT or CGTGT), which is recognized by 202 calmodulin (CaM)-binding transcription activators (CAMTAs) that are conserved from 203 plants to mammals ${ }^{29-33}$ (Fig. 3a). The Arabidopsis transcription factor CAMTA3 (also named 
SIGNAL RESPONSIVE1 [SR1]) is a negative regulator of plant immunity because camta3 null mutants exhibit constitutive expression of defence-related genes and enhanced resistance to virulent $P$. syringae infection ${ }^{34,35}$. CAMTA transcription factors possess a CaM-binding

207 (CaMB) domain and an IQ domain to which CaM binds in a calcium-dependent manner to 208 negate their function (Supplementary Fig. 3a). Mutation of the IQ domain, such as in CAMTA3 ${ }^{\mathrm{A} 855 \mathrm{~V}}$, suppresses the constitutive expression of defence-related genes seen in the camta 2 camta 3 double mutant when expressed in this background but is no longer regulated

211 by calcium-mediated responses ${ }^{36,37}$. In agreement with our promoter analysis, $28.7 \%$ of constitutively upregulated genes $(309 / 1,075$ genes) in the camtal camta 2 camta 3 triple

213 mutant overlapped with raindrop- and MS-induced genes detected in wild-type plants ${ }^{38}$

214 (Supplementary Fig. 3b, Supplementary Table 7). Upon application of raindrops and MS,

$215 W R K Y 33$ and CBP60g transcript levels were significantly reduced in plants expressing the $216 C A M T A 3^{A 855 V}$ variant compared to a CAMTA3-GFP transgenic line expressing a transgene 217 that complemented the phenotype of the camta 2 camta3 mutant (Fig. 3b, c), suggesting that 218 CAMTA3 is involved in mechanotransduction.

To confirm whether CAMTA3 directly targets mechanosensitive genes, we 220 investigated the genome-wide distribution of CAMTA3-binding sites by chromatin 221 immunoprecipitation followed by deep sequencing (ChIP-seq) using CAMTA3 ${ }^{A 855 V}$-GFP 222 plants, as the mutant protein stably represses the transcription of CAMTA3-regulated genes. 223 With the aid of model-based analysis of ChIP-seq (MACS2) software, we identified 2,641 224 and 2,728 CAMTA3-binding genes, respectively, in two replicates $(P<0.05)$; about 40\% of 225 these peaks are located in the promoter regions and another $30 \%$ in gene bodies 226 (Supplementary Fig. 3c, Supplementary Table 8). The overlap between the two replicates 227 highlighted 2,011 CAMTA3-targeted genes that included 272 raindrop- and 297 MS-induced 

CAMTA3 regulates the transcription of mechanosensitive genes.

To validate the results from the promoter analysis of mechanosensitive genes, we next investigated specific DNA sequences to which CAMTA3 selectively binds by analysing CAMTA3-binding peaks by Multiple EM for Motif Elicitation (MEME)-ChIP (Methods). We again identified the CGCG box (CGCGT or CGTGT) as the motif with the highest enrichment score $\left(3.4 \times 10^{-44}\right)$ (Fig. 3e). The subsequent visualization of ChIP-seq profiles via the Integrative Genomics Viewer $(\mathrm{IGV})^{39}$ demonstrated that CAMTA3 is primarily enriched at the CGCG boxes of mechanosensitive genes, including $\mathrm{TCH} 2, \mathrm{TCH} 4, \mathrm{CAM}$, 237 CBP60g, CALMODULIN LIKE 23 (CML23), and WRKY40 (Fig. 3f). GO analysis on 314 238 CAMTA-targeted genes (Fig. 3d, shown in red) to define the biological functions of these 239 genes showed a significant enrichment in categories related to immune and environmental 240 responses (Supplementary Fig. 3d, e). We thus investigated whether CAMTA3 is required 241 for the immune responses. camta2 camta3 CAMTA3-GFP transgenic plants effectively 242 mounted an enhanced disease resistance against $P$. syringae in response to MS, while camta2 243 camta3 $C A M T A 3^{A 855 V}$-GFP plants were significantly compromised in resistance (Fig. $3 \mathrm{~g}$ ).

244 These results demonstrate that CAMTA3 negatively regulates the plant immune responses 245 by binding to the CGCG box in raindrop- and MS-induced gene promoters and represses the 246 expression of these genes.

247 Since mechanostimulation rapidly activates MPK3/MPK6 (Fig. 2d, e), we 248 investigated whether CAMTA3 mediates the activation of these MPKs. Using camta2 249 camta3 CAMTA3-GFP and camta2 camta3 CAMTA3 ${ }^{A 855 V}-G F P$, we detected the 250 phosphorylation of MPK3/MPK6 independently of CAMTA3 activity (Supplementary Fig. 251 3f). In addition, the calcium ionophore A23187 clearly induced the phosphorylation of MPK3 
and MPK6 (Supplementary Fig. 3g). These results suggested that the mechanotransduction initiated by raindrops and MS may cause a $\mathrm{Ca}^{2+}$ influx that negates the repressive effect of CAMTA3 and concomitantly activates the MAPK cascade, as previously proposed ${ }^{26}$.

\section{MS initiates intercellular calcium waves concentrically away from trichomes}

To visualize how mechanostimulation induces the expression of immune genes in planta, we generated Arabidopsis transgenic lines with the promoter sequences of WRKY33 and CBP60g driving the expression of nucleus-targeted enhanced YELLOW FLUORESCENT PROTEIN (YFP-NLS) (WRKY33pro:EYFP-NLS and CBP60gpro:EYFP-NLS). WRKY33 expression is regulated by both MPK3/MPK6 and CAMTA3 (Supplementary Table 5, Supplementary Table 8), while CBP60g is not mediated by MPK3/MPK6 (Supplementary Table 5). When half leaves were gently brushed (Supplementary Fig. 1c), we detected YFP fluorescence in the WRKY33pro:EYFP-NLS and CBP60gpro:EYFP-NLS transgenic lines as localized, clustered groups of cells only in the brushed half (Fig. 4a, Supplementary Fig. 4a). Closer inspection of the stimulated regions revealed that both genes were induced in cells surrounding trichomes, hair-like structures projecting outward from the epidermal surface (Fig. 4b, c, Supplementary Fig. 4b, c).

Trichomes function as chemical and physical barriers against insect feeding and are likely involved in drought tolerance and protection against ultraviolet irradiation ${ }^{40,41}$. Mechanostimulation of a single trichome induces $\mathrm{Ca}^{2+}$ oscillations within the proximal skirt cells that surround the base of trichomes ${ }^{42}$, suggesting that the mechanical force could be focused on only skirt cells (Supplementary Fig. 5). However, since mechanostimulation by raindrops and MS confers resistance to pathogens in whole leaves, we hypothesized that trichomes activate a $\mathrm{Ca}^{2+}$ signal in a large area of leaves, as shown in Figure 4a. 
To visualize changes in cytosolic $\mathrm{Ca}^{2+}$ concentrations $\left(\left[\mathrm{Ca}^{2+}\right]_{\text {cyt }}\right)$ induced by MS on

277 the leaf surface, we used transgenic Arabidopsis expressing the GFP-based $\left[\mathrm{Ca}^{2+}\right]_{\text {cyt }}$ indicator GCaMP $3^{43,44}$. Leaf brushing induced a marked increase of $\left[\mathrm{Ca}^{2+}\right]_{\mathrm{cyt}}$ in the surrounding leaf

279 area of trichomes 1 min after stimulation (Fig. 4d, Supplementary Video 1). Flicking a single

280 trichome with a silver chloride wire triggered an intercellular calcium wave that propagated

281 concentrically away from the trichome and surrounding skirt cells at a speed of $1.0 \mu \mathrm{m} / \mathrm{s}$ (Fig.

282 4e, f, Supplementary Video 2). This pattern showed striking consistency with the area of 283 induction observed with the WRKY33pro:EYFP-NLS and CBP60gpro:EYFP-NLS reporters 284 (Fig. 4a, b; Supplementary Fig. 4a, b). The base of trichomes exhibited a rapid and transient 285 increase in $\left[\mathrm{Ca}^{2+}\right]_{\text {cyt }}$ before the concentric propagation of calcium waves was initiated (Fig. 286 4g, Supplementary Video 3).

\section{Trichomes are mechanosensory cells activating plant immunity}

To investigate the possible involvement of trichomes in mechanosensation in Arabidopsis leaves and activation of the immune response, we observed calcium waves using the 291 knockout mutant of GLABROUS1 $(G L 1)^{45}$, which lacks trichomes. The gl1 mutant exhibits

292 effective basal resistance comparable to that of wild-type Col-0 plants ${ }^{46}$, and its local 293 resistance to Psm ES4326 and A. brassicicola Ryo-1 is similar to the levels of Col-0 plants 294 (Supplementary Fig. 6). The mechanostimulation-induced propagation of concentric calcium 295 waves was compromised in the gll mutant (Fig. 5a, b), confirming that trichomes are true 296 MS sensors and initiate calcium waves (Supplementary Videos 4, 5). Furthermore, 297 approximately $70.5 \%$ of mechanosensitive genes were expressed in a trichome-dependent 298 manner (Fig. 5c, Supplementary Fig. 7a, Supplementary Table 9), and transcript levels of 18 299 representative mechanosensitive immune genes were markedly lower at all time points in the 

wild-type plants, the transcription of raindrop-induced $W R K Y 33, W R K Y 40$, and $C B P 60 g$, as

303 well as the activation of MPK3/MPK6 by MS, was also significantly reduced in the $g l l$ 304 mutant (Fig. 5e, f, Supplementary Fig. 7b). Moreover, MS-induced resistance against Psm 305 ES4326 infection was abrogated in the gll mutant (Fig. 5g). As with Psm ES4326, the 306 application of MS to wild-type plants prior to inoculation with A. brassicicola significantly 307 limited lesion development, whereas the gll mutant did not show enhanced disease resistance 308 in response to MS (Fig. 5h).

Our work highlights a novel layer of plant immunity that is triggered by an 310 unexpected function of trichomes as mechanosensory cells. When trichomes are 311 mechanically stimulated, intercellular calcium waves are concentrically propagated away 312 from the trichomes, followed by the activation of CAMTA3-dependent immune responses 313 (Fig. 6). Rapid phosphorylation of MAPKs also is a prerequisite for mechanosensitive gene expression, as MPK3/MPK6 mediate the phosphorylation of mechanosensitive WRKY33 for

315 its activation ${ }^{47,48}$. This notion is supported by the finding that the expression of 252 genes 316 among 917 raindrop- and MS-induced genes is regulated by MPK3/MPK6 (Supplementary 317 Fig. 2a), and their promoter sequences possess the W-box (TTGACC) for WRKYs as the 318 most enriched cis-regulatory elements (Supplementary Fig. 8). The molecular mechanism by 319 which calcium mediates the activation of MPK3/MPK6 has yet to be elucidated. Mechanostimulation by repeatedly bending leaves confers resistance to the 321 necrotrophic pathogen Botrytis cinerea via JA accumulation ${ }^{49}$. In addition, a subset of JA322 responsive genes upregulated by water spray is mediated by $\mathrm{MYC} 2 / \mathrm{MYC} 3 / \mathrm{MYC} 4$ 323 transcription factors ${ }^{20}$. These observations strongly indicate that mechanosensation causes 
324 profound JA-dependent changes in gene transcription, promoting plant immune responses to necrotrophic pathogens. The JA- and MYC-dependent pathway does not play a major role in the expression of mechanosensitive $T C H$ genes, however, indicating that mechanotransduction is regulated by other signaling pathways. Our work demonstrated that raindrops and MS only partially activate the JA signal but rather strongly induce a PTI-like response via the $\mathrm{Ca}^{2+}$ - and CAMTA3-dependent pathway, which is highly effective against both necrotrophs and biotrophs (Fig. 2g-i). Because rain disseminates diverse pathogens with different parasitic strategies, including fungi, bacteria, and virus ${ }^{50,51}$, it is highly reasonable that plants perceive raindrops as a risk factor and activate broad-spectrum resistance.

Plants possess mechanosensory cells with a variety of functions, such as flower antennas of Catasetum species for pollination, tentacles of Drosera rotundifolia for insect trapping, root hairs of Arabidopsis for water tracking, and red cells of Mimosa pudica for evading herbivores ${ }^{52}$. The carnivorous Venus flytrap (Dionaea muscipula) captures insects by sensing mechanostimulation via sensory hairs on leaf lobes ${ }^{53}$. To monitor diverse MS applied to plants, several sensing mechanisms have been proposed that include the detection of cell wall components, distortion of the plasma membrane, and the displacement of the

340 plasma membrane against the cell wall ${ }^{54}$. In all these systems, a transient increase in $\left[\mathrm{Ca}^{2+}\right]_{\mathrm{cyt}}$

341 is thought to play a pivotal role in short- and long-term responses. Indeed, two successive 342 stimulations of sensory hairs of the flytrap are required to meet the threshold of $\left[\mathrm{Ca}^{2+}\right]_{\mathrm{cyt}}$ for 343 rapid closure of the leaf blade ${ }^{53,55}$. As the trichome on the leaf surface is widely conserved 344 among many land plants, there may be a common and novel intercellular network of cell-cell communication that initiates calcium waves for activating immune responses. 


\section{Contact for reagents and subject details}

348 Further information and requests for reagents may be directed to and will be fulfilled by the

349 corresponding authors Yasuomi Tada (ytada@gene.nagoya-u.ac.jp) and Mika Nomoto

350 (nomoto@gene.nagoya-u.ac.jp).

Experimental model and subject details

Plants

Arabidopsis thaliana accession Columbia-0 (Col-0) was the background for all plants used in this study. WRKY33pro:EYFP-NLS (Col-0) and CBP60gpro:EYFP-NLS (Col-0) were generated as previously described ${ }^{56}$. 35Spro:GCaMP3 (Col-0), gl1 [Col(gll)], camta2 camta3 CAMTA3pro:CAMTA3-GFP, and camta2 camta3 CAMTA3pro:CAMTA3 ${ }^{A 855 V}-G F P$ were previously reported $^{36,38}$. The Arabidopsis mutants fls2 (SALK_093905) and bak1-3 (SALK_034523) were obtained from the Arabidopsis Biological Resource Center (ABRC). 35Spro:GCaMP3 was introduced into the gll mutant background by crossing. The selection

360 of homozygous lines was performed by genotyping using primers listed in Supplementary

361 Table 10. Plants were grown on soil (peat moss; Super Mix A and vermiculite mixed 1:1) at $36222^{\circ} \mathrm{C}$ under diurnal conditions (16-h-light/8-h-dark cycles) with 50-70\% relative humidity. 363 WRKY33pro:EYFP-NLS (Col-0) and CBP60gpro:EYFP-NLS (Col-0) were sown on soil and 364 grown in a growth room at $23^{\circ} \mathrm{C}$ in constant light as previously described ${ }^{56} .35$ Spro:GCaMP3 365 (Col-0) and 35Spro:GCaMP3 (gll) were grown on Murashige and Skoog (MS) plates [1\% $366(\mathrm{w} / \mathrm{v})$ sucrose, $0.01 \%(\mathrm{w} / \mathrm{v})$ myoinositol, $0.05 \%(\mathrm{w} / \mathrm{v}) \mathrm{MES}$, and $0.5 \%(\mathrm{w} / \mathrm{v})$ gellan gum $\mathrm{pH}$ $3675.8]$ as previously described ${ }^{44,57}$. 
Reverse osmosis (RO) water was kept in a $500 \mathrm{~mL}$ beaker until the water temperature reached room temperature $\left(22^{\circ} \mathrm{C}\right)$. A transfusion set (NIPRO Infusion Set TI-U250P, Nipro, Osaka,

371 Japan) was installed on a steel stand with the beaker at a height of $1.2 \mathrm{~m}$ (H-type Stand I3,

372 As One, Osaka, Japan) and was adjusted to release $13 \mu \mathrm{L}$ water droplets (Supplementary Fig.

373 1a). In this setting, the applied mechanical energy to the leaf surface is equivalent to one in 374 which $5.8 \mu \mathrm{L}$ of raindrops reach a terminal velocity of $6.96 \mathrm{~m} / \mathrm{s}^{58}$. This size raindrop is 375 frequently observed in nature; thus, the impact of simulated rain is comparable with that of 376 true $\operatorname{rain}^{58}$. The adaxial side of leaves from 4-week-old plants was treated with 10 droplets 377 for RNA-seq, and 1, 4 or 10 droplets for quantitative RT-PCR (RT-qPCR). The adaxial side 378 of leaves from 4-week-old plants was treated with one falling or static droplet 379 (Supplementary Fig. 1b). Sample leaves were collected 15 min after treatment and stored at $380 \quad-80{ }^{\circ} \mathrm{C}$ until use.

\section{Brush treatment}

382 The adaxial side of leaves from 4-week-old plants was brushed once for RNA-seq and 4 for 383 RT-qPCR along the main veins at an angle of $30-40^{\circ}$ (KOWA nero nylon drawing pen flat

384 12, Kowa, Aichi, Japan) (Supplementary Fig. 1c). Sample leaves were collected 15-, 30- and $38560 \mathrm{~min}$ after treatment for RNA-seq and $15 \mathrm{~min}$ for RT-qPCR, and stored at $-80^{\circ} \mathrm{C}$ until use.

\section{RNA-seq library construction}

387 Total RNA was extracted from 80-100 mg frozen samples using Sepasol-RNA I Super G 388 (Nacalai Tesque, Kyoto, Japan) and the TURBO DNase free kit (Thermo Fisher Scientific, 389 IL, USA) according to the manufacturers' protocols. Total RNA was further purified with 390 the RNeasy RNA Isolation Kit (QIAGEN, Hilden, Germany) and assessed for quality and 391 quantity with a Nanodrop spectrophotometer (Thermo Fisher Scientific). We used $1 \mu \mathrm{g}$ total 

cDNA synthesis with the NEBNext Ultra DNA Library Prep Kit for Illumina (New England the manufacturer's protocols. For the analysis of raindrop- and MS-induced gene expression, the amount of cDNA was determined on an Agilent 4150 TapeStation System (Agilent, CA, USA). cDNA libraries were sequenced as single-end reads for 81 nucleotides on an Illumina reference genome (TAIR10, http://www.arabidopsis.org/) online (BaseSpace, Illumina, https://basespace.illumina.com/). Pairwise comparisons between samples were performed

402 with the EdgeR ${ }^{59}$ package on the web (Degust, https://degust.erc.monash.edu/). For the 403 comparative analysis of differentially expressed genes between leaves in the gll mutant and 404 Col-0, the amount of cDNA was determined by the QuantiFluor dsDNA System (Promega, 405 WI, USA). cDNA libraries were sequenced as single-end reads for 36 nucleotides on an 406 Illumina Nextseq 500 (Illumina). The reads were mapped to the Arabidopsis thaliana reference genome (TAIR10) via Bowtie ${ }^{60}$ with the options "--all --best --strata". Pairwise

408 comparisons between samples were performed with the EdgeR package in the R program ${ }^{59}$.

409 Enrichment of GO categories for biological processes was determined using BiNGO 410 (http://www.psb.ugent.be/cbd/papers/BiNGO/Home.html) $(P<0.05)^{61}$.

\section{Re-analysis of immune-related transcriptome datasets}

412 We used the following public transcriptome datasets for the comparative analysis with the 413 RNA-seq data obtained in this study: 10-day-old Arabidopsis seedlings treated with $1 \mu \mathrm{M}$ 414 flg22 (Array Express; E-NASC-76) ${ }^{62}$, 8-day-old Arabidopsis seedlings treated with $40 \mu \mathrm{M}$ 415 chitin (Gene Expression Omnibus GSE74955), leaves from 4-week-old Arabidopsis plants 
416 inoculated with Pseudomonas syringae pv. maculicola (Psm) ES4326 (24 h post inoculation)

417 (GSE18978), 2-week-old Arabidopsis seedlings treated with 0.5 mM SA or $50 \mu$ M JA (DNA

418 Data Bank of Japan DRA003119), 12-day-old Arabidopsis GVG-NtMEK2 ${ }^{D D}$ seedlings

419 treated with $2 \mu \mathrm{M}$ DEX for 0 and 6 h (NCBI Sequence Read Archive SRP111959), and 4-

420 week-old Arabidopsis camtal camta2 camta3 triple mutant (GSE43818). The overlaps

421 between differentially expressed genes in each transcriptome dataset were evaluated as Venn

422 diagrams (http://bioinformatics.psb.ugent.be/webtools/Venn/).

\section{RT-qPCR}

424 Total RNA was extracted from 30-40 mg leaf tissues with Sepasol-RNA I Super G and the 425 TURBO DNase free kit (Thermo Fisher Scientific) according to the manufacturer's protocols, 426 followed by reverse transcription with the PrimeScript RT reagent kit (Takara Bio, Shiga, 427 Japan) using oligo dT primers. RT-qPCR was performed on the first-strand cDNAs diluted 428 20-fold in water using KAPA SYBR FAST qPCR Master Mix (2x) kit (Roche, Basel, 429 Switzerland) and gene-specific primers in a LightCycler 96 (Roche). Primer sequences are $430 \quad$ listed in Supplementary Table 10.

\section{Quantification of plant hormones}

432 The adaxial side of leaves from 4-week-old plants was treated with 10 raindrops (raindrop),

433 brushed once (MS), and cut (wounding). Sample leaves (0.07-0.1 g) were collected 5 min 434 after treatment and stored at $-80^{\circ} \mathrm{C}$ until use. SA, JA, JA-Ile, ABA, IAA, and GA4 were 435 extracted and purified by solid-phase extraction. The contents of these hormones were 436 quantified using liquid chromatography-electrospray tandem mass spectrometry (LC-ESI-

437 MS/MS) (triple quadrupole mass spectrometer with 1260 high-performance LC, G6410B; 438 Agilent Technologies Inc., CA, USA), as previously reported ${ }^{63}$. 


\section{ChIP assay}

Approximately $0.7 \mathrm{~g}$ of 2-week-old camta2 camta3 CAMTA3pro:CAMTA3 ${ }^{A 855 V}-G F P$ seedlings was fixed in $25 \mathrm{~mL} \mathrm{1 \%}$ formaldehyde under vacuum for three cycles of $2 \mathrm{~min} \mathrm{ON} / 2$ min OFF using an aspirator (SIBATA, Tokyo, Japan). Subsequently, $1.5 \mathrm{~mL}$ of $2 \mathrm{M}$ glycine was added to quench the cross-linking reaction under vacuum for $2 \mathrm{~min}$. The samples were then washed with $50 \mathrm{~mL}$ double-distilled water and stored at $-80^{\circ} \mathrm{C}$ until use. Frozen samples were ground to a fine powder with a mortar and pestle in liquid nitrogen and dissolved in 2.5 $\mathrm{mL}$ nuclei extraction buffer $(10 \mathrm{mM}$ Tris- $\mathrm{HCl} \mathrm{pH} 8.0,0.25 \mathrm{M}$ sucrose, $10 \mathrm{mM} \mathrm{MgCl} 2,40$ $\mathrm{mM} \beta$-mercaptoethanol, protease inhibitor cocktail $)^{64}$. Samples were filtered through two layers of Miracloth (Calbiochem, CA, USA) and centrifuged at 17,700 $\mathrm{g}$ at $4^{\circ} \mathrm{C}$ for $5 \mathrm{~min}$. The pellets were resuspended in $75 \mu \mathrm{L}$ nuclei lysis buffer [50 mM Tris-HCl pH 8.0, $10 \mathrm{mM}$ EDTA, 1\% (w/v) SDS]. After incubation first at room temperature for $20 \mathrm{~min}$ and then on ice for $10 \mathrm{~min}$, the samples were mixed with $225 \mu \mathrm{L}$ ChIP dilution buffer without Triton [16.7 mM Tris-HCl pH 8.0, $167 \mathrm{mM} \mathrm{NaCl,} 1.2 \mathrm{mM}$ EDTA, 0.01\% (w/v) SDS]. Chromatin

454 (Cosmo Bio, Tokyo, Japan) to produce DNA fragments, followed by the addition of $375 \mu \mathrm{L}$ 455 ChIP dilution buffer without Triton, $200 \mu \mathrm{L}$ ChIP dilution buffer with Triton [16.7 mM Tris$456 \mathrm{HCl} \mathrm{pH}$ 8.0, $167 \mathrm{mM} \mathrm{NaCl}, 1.2 \mathrm{mM}$ EDTA, 0.01\% (w/v) SDS, 1.1\% (w/v) Triton X-100], and $35 \mu \mathrm{L} 20 \%(\mathrm{w} / \mathrm{v})$ Triton X-100. After centrifugation at $17,700 \mathrm{~g}$ at $4^{\circ} \mathrm{C}$ for $5 \mathrm{~min}, 900$ $\mu \mathrm{L}$ solubilized sample was split into two $2.0 \mathrm{~mL}$ PROKEEP low-protein-binding tubes (Watson Bio Lab USA, CA, USA) and incubated with $0.75 \mu \mathrm{L}$ anti-GFP antibody (for 460 immunoprecipitation [IP]) (ab290; Abcam, Cambridge, UK) or Rabbit IgG-Isotype Control 461 (Input) (ab37415; Abcam) for $4.5 \mathrm{~h}$ with gentle rocking, and an $18 \mu \mathrm{L}$ aliquot was used as 462 the input control. Then, samples from camta2 camta3 CAMTA3pro:CAMTA3 ${ }^{A 855 V}-G F P$ were 463 mixed with $50 \mu \mathrm{L}$ of a slurry of Protein A agarose beads (Upstate, Darmstadt, Germany) and 
464 incubated at $4^{\circ} \mathrm{C}$ for $1 \mathrm{~h}$ with gentle rocking. Beads were washed twice with $1 \mathrm{~mL}$ low-salt

465

466

467

468

469

470

471

472

473

474

475

476

477

478

479

480

481

482

483

484

485

486 wash buffer [20 mM Tris- $\mathrm{HCl} \mathrm{pH} 8.0,150 \mathrm{mM} \mathrm{NaCl}, 2 \mathrm{mM}$ EDTA, 0.1\% (w/v) SDS, 1\% (w/v) Triton X-100], twice with $1 \mathrm{~mL}$ high-salt wash buffer $[20 \mathrm{mM}$ Tris-HCl pH 8.0, 500 $\mathrm{mM} \mathrm{NaCl}, 2 \mathrm{mM}$ EDTA, 0.1\% (w/v) SDS, 1\% (w/v) Triton X-100], twice with $1 \mathrm{~mL} \mathrm{LiCl}$ wash buffer [10 mM Tris-HCl pH 8.0, $0.25 \mathrm{M} \mathrm{LiCl,} 1 \mathrm{mM}$ EDTA, 1\% (w/v) sodium deoxycholate, $1 \%(\mathrm{w} / \mathrm{v})$ Nonidet P-40], and twice with $1 \mathrm{~mL}$ TE buffer [10 mM Tris-HCl pH 8.0, $1 \mathrm{mM}$ EDTA]. After washing, beads were resuspended in $100 \mu \mathrm{L}$ elution buffer [1\% $\left.(\mathrm{w} / \mathrm{v}) \mathrm{SDS}, 0.1 \mathrm{M} \mathrm{NaHCO}_{3}\right]$ and incubated at $65^{\circ} \mathrm{C}$ for $30 \mathrm{~min}$. For the input controls, 41.1 $\mu \mathrm{L}$ TE buffer, $8.7 \mu \mathrm{L} 10 \%$ (w/v) SDS, and $21 \mu \mathrm{L}$ elution buffer were added to $18 \mu \mathrm{L}$ of each solubilized sample. Both supernatant and input samples were mixed with $4 \mu \mathrm{L}$ of $5 \mathrm{M} \mathrm{NaCl}$ and incubated at $65^{\circ} \mathrm{C}$ overnight to reverse the cross-linking, followed by digestion with 1 $\mu \mathrm{L}$ Proteinase $\mathrm{K}(20 \mathrm{mg} / \mathrm{ml})$ (Invitrogen, CA, USA) at $37^{\circ} \mathrm{C}$ for $1 \mathrm{~h}$. ChIP samples were mixed with $500 \mu \mathrm{L}$ Buffer NTB and purified using the PCR clean-up gel extraction kit following the manufacturer's instructions (MACHEREY-NAGEL, Düren, Germany).

\section{ChIP-seq library construction}

ChIP-seq libraries for the input and two biological replicates were constructed from $2 \mathrm{ng}$ purified DNA samples with the NEB Ultra II DNA Library Prep Kit for Illumina (New England Biolabs) according to the manufacturer's instructions. The amount of DNA was determined on an Agilent 4150 TapeStation System (Agilent). All ChIP-seq libraries were sequenced as 81-nucleotide single-end reads using an Illumina NextSeq 550 system.

\section{Analysis of ChIP-seq}

Reads were mapped to the Arabidopsis thaliana reference genome (TAIR10, http://www.arabidopsis.org/) using Bowtie2 with default parameters ${ }^{60}$. The Sequence 

(BAM) format file by SAMtools ${ }^{65}$. To visualize mapped reads, Tiled Data Files (TDF) file were generated from each BAM file using the igvtools package in the Integrative Genome Browser $(\mathrm{IGV})^{39}$. ChIP-seq peaks were called by comparing the IP with the Input using Model-based Analysis of ChIP-Seq (MACS2) with the “-p 0.05 -g 1.19e8” option $(P<$ $0.05)^{66}$. The peaks were annotated using the nearest gene using the Bioconductor and the ChIPpeakAnno packages in the R program, from which we identified 2,011 genes detected in both biological replicates. Enrichment of GO categories of the set of 314 genes overlapping between raindrop- and MS-induced genes for biological processes was determined using BiNGO (http://www.psb.ugent.be/cbd/papers/BiNGO/Home.html) ${ }^{61}$. Sequences of the

497 peaks were extracted from the Arabidopsis thaliana genome as FASTA files with Bedtools ${ }^{67}$. 498 To identify the candidates of CAMTA3-binding motifs, the FASTA files were subjected to MEME (Multiple EM for Motif Elicitation)-ChIP with the default parameter (-meme-minw 6-meme-maxw 10) ${ }^{68}$, and a density plot of the distribution of the motifs was generated.

\section{Immunoblot analysis for detection of MPK3 and MPK6 phosphorylation}

502 The adaxial side of leaves from 4-week-old plants was brushed four times or treated with 503 four raindrops, and samples (0.1-0.15 g) were snap-frozen in liquid nitrogen. Total proteins 504 were extracted in protein extraction buffer [50 mM Tris- $\mathrm{HCl} \mathrm{pH} \mathrm{7.5,} 150 \mathrm{mM} \mathrm{NaCl}, 2 \mathrm{mM}$ 505 DTT, $2.5 \mathrm{mM} \mathrm{NaF}, 1.5 \mathrm{mM} \mathrm{Na}_{3} \mathrm{VO}_{4}, 0.5 \%$ (w/v) Nonidet P-40, $50 \mathrm{mM} \beta$-glycerophosphate, 506 and proteinase inhibitor cocktail] and centrifuged once at $6,000 \mathrm{~g}, 4^{\circ} \mathrm{C}$, for $20 \mathrm{~min}$ and twice 507 at $17,000 \mathrm{~g}, 4^{\circ} \mathrm{C}$ for $10 \mathrm{~min}$. The supernatant was mixed with SDS sample buffer [50 mM 508 Tris- $\mathrm{HCl} \mathrm{pH}$ 6.8, 2\% (w/v) SDS, 5\% (w/v) glycerol, 0.02\% (w/v) bromophenol blue, and $509200 \mathrm{mM} \mathrm{DTT}]$ and heated at $70^{\circ} \mathrm{C}$ for $20 \mathrm{~min}$. The protein samples were subjected to SDS510 PAGE electrophoresis and transferred onto a nitrocellulose membrane (GE Healthcare, IL, 
511 USA). The membrane was incubated with an anti-phospho-p44/42 MAPK polyclonal

512 antibody (Cell Signalling Technology, MA, USA) (1:1,000 dilution) and goat anti-rabbit

513 IgG(H+L)-HRP secondary antibody (BIO-RAD, CA, USA) (1:2,000 dilution). The bands for

514 MPK3/6 were visualized using chemiluminescence solution mixed 5:1 with ImmunoStar

515 Zeta (FUJIFILM Wako Chemicals, Osaka, Japan) and SuperSignal West Dura Extended

516 Duration Substrate (Thermo Fisher Scientific). The Rubisco bands were stained with

517 Ponceau S (Merck Sharp \& Dohme Corp., NJ, USA) as a loading control. The

518 phosphorylation levels of MPK3 and MPK6 were quantified with the blot analysis plug-in in

519 ImageJ (https://imagej.nih.gov/ij/).

\section{Treatment with the calcium ionophore A23187}

521 Twelve-day-old Col-0 seedling was treated with $50 \mu \mathrm{M}$ calcium ionophore A23187 for 15-,

522 30- and $60 \mathrm{~min}$. Samples were processed for the phosphorylation of MPK3 and MPK6 as

523 described in the "Immunoblot analysis for detection of MPK3 and MPK6 phosphorylation"

524 section. The leaf tissue was stored at $-80^{\circ} \mathrm{C}$ until use.

\section{$525 \quad$ Promoter-reporter imaging}

526 The 3.0-kbp promoters for WRKY33 and CBP60g, both of which covered the previously

527 analyzed respective regulatory sequences, were amplified from Col-0 genomic DNA by PCR

528 and cloned into the pENTR/D-TOPO vector (Invitrogen). The promoter regions were

529 recombined using Gateway technology into the binary vector pBGYN. The resulting 530 pBGYN-pWRKY33-YFP-NLS and pBGYN-pCBP60g-YFP-NLS vectors were introduced

531 into Agrobacterium tumefaciens GV3101 (pMP90) and then into Arabidopsis Col-0 plants

532 using the floral dip method. A representative homozygous line was selected for each

533 construct for further detailed analyses. 

stereomicroscope (Leica Microsystems, Wetzlar, Germany) and DFC365FX CCD camera

536 (Leica Microsystems) in 12-bit mode. Chlorophyll autofluorescence and YFP fluorescence

537 were detected through Texas Red (TXR) (excitation 560/40 nm, extinction $610 \mathrm{~nm}$ ) and YFP

538 (excitation 510/20 nm, extinction 560/40 nm) filters (Leica Microsystems). To image

539 fluorescence emanating from the WRKY33pro:EYFP-NLS (Col-0) and CBP60gpro:EYFP-

$540 N L S\left(\right.$ Col-0) plants ${ }^{56}$, the leaves of 3-week-old Arabidopsis plants were brushed 10 times at

541 an interval of $15 \mathrm{~min}$ for $2 \mathrm{~h}$ or left untreated.

\section{$542 \quad$ Promoter analysis}

543 The statistical analysis for overrepresented transcriptional regulatory elements across 544 transcriptome datasets described above was calculated using a prediction program as 545 previously reported ${ }^{32}$. The $P$ values were calculated using Statistical Motif Analysis in 546 Promoter or $\quad$ Upstream $\quad$ Sequences

547 (https://www.arabidopsis.org/tools/bulk/motiffinder/index.jsp). Figures of promoter motif 548 sequences are generated with WebLogo (https://weblogo.berkeley.edu/logo.cgi).

\section{Real-time $\left[\mathrm{Ca}^{2+}\right]_{\text {cyt }}$ imaging}

550 We used 4-week-old and 3-week-old plants expressing the GFP-based cytosolic $\mathrm{Ca}^{2+}$ 551 concentration $\left(\left[\mathrm{Ca}^{2+}\right]_{\mathrm{cyt}}\right)$ indicator $\mathrm{GCaMP} 3^{43,44}$. To image the fluorescence from the 552 GCaMP3 reporter (in Col-0 and $g l 1$ ) in whole leaves, the adaxial sides of leaves from 4553 week-old plants were brushed. To monitor the calcium waves propagating from trichomes, a 554 single trichome from a 2-week-old seedling was flicked with a silver chloride wire. Samples 555 were imaged with a motorized fluorescence stereomicroscope (SMZ-25; Nikon, Tokyo, 556 Japan) equipped with a $1 \times$ objective lens $(\mathrm{NA}=0.156$, P2-SHR PLAN APO; Nikon) and an 
557 sCMOS camera (ORCA-Flash 4.0 V2; Hamamatsu Photonics, Shizuoka, Japan) as 558 described ${ }^{44}$.

\section{$559 \quad$ Propidium iodide staining}

560 A stock solution of $10 \mathrm{mM}$ propidium iodide (PI) was prepared with phosphate-buffered 561 saline (PBS). Rosette leaves of 4-week-old Col-0 plants were cut into $5 \mathrm{~mm}$ squares, floated 562 in a glass petri dish with $20 \mu \mathrm{M}$ PI solution, and incubated for $1 \mathrm{~h}$ at room temperature. 563 Stained tissues were observed under the all-in-one fluorescence microscope (BZ-X800; 564 KEYENCE CORPORATION, Osaka, Japan) equipped with a 20x objective lens (CFI S Plan 565 Fluor LWD ADM 20XC, Nikon) and TRITC dichroic mirror (excitation 545/25 nm, 566 extinction 605/70 nm) (KEYENCE).

\section{Bacterial infection}

568 MS were applied to the adaxial leaf surface of 4-week-old plants by brushing 4 times at an 569 interval of $15 \mathrm{~min}$ for $3 \mathrm{~h}$. Sample leaves were then inoculated by infiltration, using a plastic 570 syringe (Terumo Tuberculin Syringe $1 \mathrm{~mL}$; TERUMO), with Psm ES4326 (OD $600=0.001)$

571 resuspended in $10 \mathrm{mM} \mathrm{MgCl}$. Bacterial growth was measured 2 days after inoculation as 572 described previously ${ }^{69}$.

\section{$573 \quad$ Fungal infection}

574 Alternaria brassicicola strain Ryo-1 was cultured on $3.9 \%(\mathrm{w} / \mathrm{v})$ potato dextrose agar plates 575 (PDA; Becton, Dickinson and Company, NJ, USA) for $4-20$ days at $28^{\circ} \mathrm{C}$ in the dark. After 576 incubation of the agar plates for 3-7 days under ultraviolet $\mathrm{C}$ light, a conidial suspension of 577 A. brassicicola was obtained by mixing with RO water ${ }^{70}$. The adaxial side of leaves from 4578 week-old plants was treated with 10 droplets or MS by brushing at an interval of 15 min for

$5793 \mathrm{~h}$, followed by spotting with $5 \mu \mathrm{L}$ conidia suspension $\left(2 \times 10^{5}\right.$ per $\left.\mathrm{mL}\right)$ of $A$. brassicicola 
on the adaxial side of leaves. Inoculated plants were placed at $22^{\circ} \mathrm{C}$ under diurnal conditions

581 (16-h-light/8-h-dark cycles) with 100\% relative humidity. The lesion size of fungal infection was measured with ImageJ 3 days after inoculation.

\section{Statistics and reproducibility}

584 GraphPad Prism 9 (GraphPad software, CA, USA) was used for all statistical analyses. Two585 sided one-way analysis of variance (one-way ANOVA) or two-way analysis of variance 586 (two-way ANOVA) was used for multiple comparisons. Unless stated otherwise, sample size $587 \mathrm{n}$ represents technical replicates. In RT-qPCR, $\mathrm{n} \geq 3$; in bacterial growth assays, $\mathrm{n}=8$; in

588 real-time $\left[\mathrm{Ca}^{2+}\right]_{\text {cyt }}$ imaging assays of 35Spro:GCaMP3 (Col-0) and 35Spro:GCaMP3 (gll),

$589 \mathrm{n}=14$ and 9, respectively; and in fungal disease propagation assays, $\mathrm{n}=29$ (Fig. $2 \mathrm{~g}$ ) and $\mathrm{n}$ $590=15$ (the other figures). All experiments were performed at least three times with similar 591 results (biological replicates). In all graphs, asterisks indicate statistical significance tested 592 by Student's $t$ test (two groups) or one/two-way ANOVA (multiple groups).

593 Reporting summary

594 Further information on research design is available in the Nature Research Reporting 595 Summary linked to this article.

\section{Date availability}

597 The authors declare that all data supporting the findings of this study are available within this 598 article and its Supplementary Information files. RNA-seq and ChIP-seq data have been 599 deposited in the DDBJ Sequence Read Archive (DRA) at the DNA Data Bank (DDBJ; 600 http://www.ddbj.nig.ac.jp/) through the accession numbers DRA011970, DRA009248 and 601 DRA011123. 
602

603

604 1. Couto, D. \& Zipfel, C. Regulation of pattern recognition receptor signalling in plants.

605

606

607

608

609

610

611

612

613

614

615

616

617

618

619

620

621

622

623

624

625

626

627

628

629

630

631

632

633

\section{References}

2. Zipfel, C. et al. Bacterial disease resistance in Arabidopsis through flagellin perception. Nature 428, 764-767 (2004).

3. Chisholm, S. T., Coaker, G., Day, B. \& Staskawicz, B. J. Host-microbe interactions: shaping the evolution of the plant immune response. Cell 124, 803-814 (2006).

4. Cui, H., Tsuda, K. \& Parker, J. E. Effector-triggered immunity: from pathogen perception to robust defense. Annu. Rev. Plant Biol. 66, 487-511 (2015).

5. Jones, J. D. \& Dangl, J. L. The plant immune system. Nature 444, 323-329 (2006).

6. Boudsocq, $\mathrm{M}$. et al. Differential innate immune signalling via $\mathrm{Ca}(2+)$ sensor protein kinases. Nature 464, 418-422 (2010).

7. Macho, A. P. \& Zipfel, C. Plant PRRs and the activation of innate immune signaling. Mol. Cell 54, 263-272 (2014).

8. Mwimba, M. et al. Daily humidity oscillation regulates the circadian clock to influence plant physiology. Nat. Commun. 9, 4290 (2018).

9. Wang, W. et al. Timing of plant immune responses by a central circadian regulator. Nature 470, 110-114 (2011).

10. Zhou, M. et al. Redox rhythm reinforces the circadian clock to gate immune response. Nature 523, 472-476 (2015).

11. Madden, L. V. Effects of rain on splash dispersal of fungal pathogens. CANADIAN J. Plant Pathol. 19, 225-230 (1997).

12. Schwartz, H. F., Otto, K. L. \& Gent, D. H. Relation of temperature and rainfall to development of Xanthomonas and Pantoea leaf blights of onion in Colorado. Plant Dis. 87, 11-14 (2003).

13. Melotto, M., Underwood, W., Koczan, J., Nomura, K. \& He, S. Y. Plant stomata function in innate immunity against bacterial invasion. Cell 126, 969-980 (2006).

14. Xin, X. F. et al. Bacteria establish an aqueous living space in plants crucial for virulence. Nature 539, 524-529 (2016).

15. Braam, J. \& Davis, R. W. Rain-, wind-, and touch-induced expression of calmodulin and calmodulin-related genes in Arabidopsis. Cell 60, 357-364 (1990). 
634 16. Jaffe, M. J. Thigmomorphogenesis: The response of plant growth and development to mechanical stimulation : With special reference to Bryonia dioica. Planta 114, 143157 (1973).

17. Sanyal, D. \& Bangerth, F. Stress induced ethylene evolution and its possible relationship to auxin-transport, cytokinin levels, and flower bud induction in shoots of apple seedlings and bearing apple trees. Plant Growth Regul. 24, 124-134 (1998).

18. Johnson, K. A., Sistrunk, M. L., Polisensky, D. H. \& Braam, J. Arabidopsis thaliana responses to mechanical stimulation do not require ETR1 or EIN2. Plant Physiol. 116, 643-649 (1998).

643 19. Lange, M. J. \& Lange, T. Touch-induced changes in Arabidopsis morphology dependent on gibberellin breakdown. Nat. Plants 1, 14025 (2015).

20. Van Moerkercke, A. et al. A MYC2/MYC3/MYC4-dependent transcription factor network regulates water spray-responsive gene expression and jasmonate levels. Proc. Natl. Acad. Sci. US A 116, 23345-23356 (2019).

21. Li, B., Meng, X., Shan, L. \& He, P. Transcriptional regulation of pattern-triggered immunity in plants. Cell Host Microbe 19, 641-650 (2016).

22. Pandey, S. P. \& Somssich, I. E. The role of WRKY transcription factors in plant immunity. Plant Physiol. 150, 1648-1655 (2009).

23. Dong, X., Mindrinos, M., Davis, K. R. \& Ausubel, F. M. Induction of Arabidopsis defense genes by virulent and avirulent Pseudomonas syringae strains and by a cloned avirulence gene. Plant Cell 3, 61-72 (1991).

24. Fu, Z. Q. \& Dong, X. Systemic acquired resistance: turning local infection into global

657 25. Howe, G. A. \& Jander, G. Plant immunity to insect herbivores. Annu. Rev. Plant Biol. 59, 41-66 (2008).

659 26. Tena, G., Boudsocq, M. \& Sheen, J. Protein kinase signaling networks in plant innate 660 immunity. Curr. Opin. Plant Biol.. 14, 519-529 (2011).

661 27. Galletti, R., Ferrari, S. \& De Lorenzo, G. Arabidopsis MPK3 and MPK6 play 662 different roles in basal and oligogalacturonide- or flagellin-induced resistance against Botrytis cinerea. Plant Physiol. 157, 804-814 (2011).

664 28. Su, J. et al. Active photosynthetic inhibition mediated by MPK3/MPK6 is critical to effector-triggered immunity. PLoS Biol. 16, e2004122 (2018). 
666 29. Bouche, N., Scharlat, A., Snedden, W., Bouchez, D. \& Fromm, H. A novel family of

667

668

669

670

671

672

673

674

675

676

677

678

679

680

681

682

683

684

685

686

687

688

689

690

691

692

693

694

695

696

697

698 calmodulin-binding transcription activators in multicellular organisms. J. Biol. Chem. 277, 21851-21861 (2002).

30. Doherty, C. J., Van Buskirk, H. A., Myers, S. J. \& Thomashow, M. F. Roles for Arabidopsis CAMTA transcription factors in cold-regulated gene expression and freezing tolerance. Plant Cell 21, 972-984 (2009).

31. Finkler, A., Ashery-Padan, R. \& Fromm, H. CAMTAs: calmodulin-binding transcription activators from plants to human. FEBS Lett. 581, 3893-3898 (2007).

32. Yamamoto, Y. Y. et al. Identification of plant promoter constituents by analysis of local distribution of short sequences. BMC Genomics 8, 67 (2007).

33. Yang, Y. et al. Genome-wide identification of CAMTA gene family members in Medicago truncatula and their expression during root nodule symbiosis and hormone treatments. Front. Plant Sci. 6, 459 (2015).

34. $\mathrm{Du}$, L. et al. $\mathrm{Ca}(2+) /$ calmodulin regulates salicylic-acid-mediated plant immunity. Nature 457, 1154-1158 (2009).

35. Galon, Y. et al. Calmodulin-binding transcription activator (CAMTA) 3 mediates biotic defense responses in Arabidopsis. FEBS Lett. 582, 943-948 (2008).

36. Kim, Y. S. et al. CAMTA-mediated regulation of salicylic acid immunity pathway genes in Arabidopsis exposed to low temperature and pathogen infection. Plant Cell 29, 2465-2477 (2017).

37. Nie, H. et al. SR1, a calmodulin-binding transcription factor, modulates plant defense and ethylene-induced senescence by directly regulating NDR1 and EIN3. Plant Physiol. 158, 1847-1859 (2012).

38. Kim, Y., Park, S., Gilmour, S. J. \& Thomashow, M. F. Roles of CAMTA transcription factors and salicylic acid in configuring the low-temperature transcriptome and freezing tolerance of Arabidopsis. Plant J. 75, 364-376 (2013).

39. Thorvaldsdottir, H., Robinson, J. T. \& Mesirov, J. P. Integrative Genomics Viewer (IGV): high-performance genomics data visualization and exploration. Brief Bioinformatics 14, 178-192 (2013).

40. Gutschick, V. P. Biotic and abiotic consequences of differences in leaf structure. New Phytol. 143, 3-18 (2002).

41. Wagner, G. J., Wang, E. \& Shepherd, R. W. New approaches for studying and exploiting an old protuberance, the plant trichome. Ann. Bot. 93, 3-11 (2004). 
42. Zhou, L. H. et al. The Arabidopsis trichome is an active mechanosensory switch. Plant Cell Environ. 40, 611-621 (2017).

43. Tian, L. et al. Imaging neural activity in worms, flies and mice with improved GCaMP calcium indicators. Nat. Methods 6, 875-881 (2009).

44. Toyota, M. et al. Glutamate triggers long-distance, calcium-based plant defense signaling. Science 361, 1112-1115 (2018).

45. Larkin, J. C., Oppenheimer, D. G., Lloyd, A. M., Paparozzi, E. T. \& Marks, M. D. Roles of the GLABROUS1 and TRANSPARENT TESTA GLABRA genes in Arabidopsis trichome development. Plant Cell 6, 1065-1076 (1994).

46. Xia, Y. et al. The glabral mutation affects cuticle formation and plant responses to microbes. Plant Physiol. 154, 833-846 (2010).

47. Mao, G. et al. Phosphorylation of a WRKY transcription factor by two pathogenresponsive MAPKs drives phytoalexin biosynthesis in Arabidopsis. Plant Cell 23, 1639-1653 (2011).

48. Tsuda, K. \& Somssich, I. E. Transcriptional networks in plant immunity. New Phytol. 206, 932-947 (2015).

49. Chehab, E. W., Yao, C., Henderson, Z., Kim, S. \& Braam, J. Arabidopsis touchinduced morphogenesis is jasmonate mediated and protects against pests. Curr. Biol. 22, 701-706 (2012).

50. Bauer, $\mathrm{H}$. et al. The contribution of bacteria and fungal spores to the organic carbon content of cloud water, precipitation and aerosols. Atmospheric Research 64, 109-119 (2002).

51. Prussin, A. J. 2nd, Marr, L. C. \& Bibby, K. J. Challenges of studying viral aerosol metagenomics and communities in comparison with bacterial and fungal aerosols. FEMS Microbiol. Lett. 357, 1-9 (2014).

52. Huynh, T.-P. \& Haick, H. Learning from an intelligent mechanosensing system of plants. Adv. Mater. Technol. 4, 1800464 (2019).

53. Scherzer, S., Federle, W., Al-Rasheid, K. A. S. \& Hedrich, R. Venus flytrap trigger hairs are micronewton mechano-sensors that can detect small insect prey. Nat. Plants 5, 670-675 (2019).

54. Bacete, L. \& Hamann, T. The Role of mechanoperception in plant cell wall integrity maintenance. Plants (Basel, Switzerland) 9, (2020). 
731 55. Suda, H. et al. Calcium dynamics during trap closure visualized in transgenic Venus

732

733

734

735

736

737

738 flytrap. Nat. Plants 6, 1219-1224 (2020).

56. Betsuyaku, S. et al. Salicylic acid and jasmonic acid pathways are activated in spatially different domains around the infection site during effector-triggered immunity in Arabidopsis thaliana. Plant Cell Physiol. 59, 8-16 (2018).

57. Murashige, T. \& Skoog, F. A revised medium for rapid growth and bio assays with Tobacco tissue cultures. Physiol. Plant. 15, $473-497$ (1962).

58. Gunn, R. \& Kinzer, G. D. The terminal velocity of fall for water droplet in stagnant air. J. Atmospheric Sci. 6, 243-248 (1949).

59. Robinson, M. D., McCarthy, D. J. \& Smyth, G. K. edgeR: a Bioconductor package for differential expression analysis of digital gene expression data. Bioinformatics 26, 139-140 (2010).

60. Langmead, B. \& Salzberg, S. L. Fast gapped-read alignment with Bowtie 2. Nat. Methods 9, 357-359 (2012).

61. Maere, S., Heymans, K. \& Kuiper, M. BiNGO: a Cytoscape plugin to assess overrepresentation of gene ontology categories in biological networks. Bioinformatics 21, 3448-3449 (2005).

62. Denoux, C. et al. Activation of defense response pathways by OGs and flg22 elicitors in Arabidopsis seedlings. Mol. Plant 1, 423-445 (2008).

63. Matsuura, T., Mori, I. C., Himi, E. \& Hirayama, T. Plant hormone profiling in developing seeds of common wheat (Triticum aestivum L.). Breeding Science 69, 601610 (2019).

64. Yamaguchi, N. et al. PROTOCOLS: Chromatin immunoprecipitation from Arabidopsis tissues. The arabidopsis book 12, e0170 (2014).

65. Li, H. et al. The Sequence Alignment/Map format and SAMtools. Bioinformatics 25, 2078-2079 (2009).

66. Zhang, Y. et al. Model-based Analysis of ChIP-Seq (MACS). Genome Biol. 9, R137 (2008).

67. Quinlan, A. R. \& Hall, I. M. BEDTools: a flexible suite of utilities for comparing genomic features. Bioinformatics 26, 841-842 (2010).

68. Machanick, P. \& Bailey, T. L. MEME-ChIP: motif analysis of large DNA datasets. Bioinformatics 27, 1696-1697 (2011). 
69. Cao, H., Bowling, S. A., Gordon, A. S. \& Dong, X. Characterization of an Arabidopsis mutant that is nonresponsive to inducers of systemic acquired resistance. Plant Cell 6, 1583-1592 (1994).

70. Hiruma, K. et al. Arabidopsis ENHANCED DISEASE RESISTANCE 1 is required for pathogen-induced expression of plant defensins in nonhost resistance, and acts through interference of MYC2-mediated repressor function. Plant J. 67, 980-992 (2011).

\section{Acknowledgements}

We thank M. F. Thomashow for the seeds of CAMTA3 variants. This work was supported by JSPS KAKENHI Grant Numbers JP23120520, JP25120718, and JP18K19334 (to Y.T.), JP15H05955 (to Y.T. and T.K.), JP19H05363, and JP21H00366 (to M.N.).

\section{Author contributions}

M.M., M.N., S.H.S., and Y.T. designed the research. M.M. and T.I. established the artificial rain device. M.M. optimized the protocols for artificial raindrop and brush treatment. M.M. and M.N. constructed the Illumina sequencing libraries for RNA-seq and ChIP-seq. T.S. performed RNA-seq and analysis. M.N. performed the ChIP-seq and analysis of CAMTA3. T.M. and I.M. performed the quantification of phytohormones. M.M., Y.H., and T.K. performed the detection of MPK3 and MPK6 phosphorylation. Y.A. and M.T. generated 35Spro:GCaMP3 (gll) plants, and M.N., M.T., and Y.A. visualized real-time $\left[\mathrm{Ca}^{2+}\right]_{\mathrm{cyt}}$. M.I. and S.B. generated the transgenic lines WRKY33pro:EYFP-NLS (Col-0) and CBP60gpro:EYFP-NLS (Col-0). M.M., M.I., and S.B. performed promoter-reporter imaging. M.N. and M.M. performed the rest of the experiments. M.M., M.N., S.H.S., and Y.T. wrote the manuscript with input from all authors. 
bioRxiv preprint doi: https://doi.org/10.1101/2021.06.13.448005; this version posted June 14, 2021. The copyright holder for this preprint (which was not certified by peer review) is the author/funder, who has granted bioRxiv a license to display the preprint in perpetuity. It is made available under aCC-BY 4.0 International license.

\section{Competing interests}

790 The authors declare no competing interests.

791 
a

\begin{tabular}{|l|c|}
\hline \multicolumn{1}{|c|}{ Induced by Raindrop } & Levels of Significance \\
\hline 1. response to chitin (GO:0010200) & $1.35 \times 10^{-50}$ \\
2. response to carbohydrate stimulus (GO:0009743) & $3.38 \times 10^{-37}$ \\
3. response to stimulus (GO:0050896) & $1.44 \times 10^{-33}$ \\
4. response to organic substance (GO:0010033) & $2.92 \times 10^{-30}$ \\
5. response to stress (GO:0006950) & $7.67 \times 10^{-29}$ \\
6. response to chemical stimulus (GO:0042221) & $4.44 \times 10^{-26}$ \\
7. defence response (GO:0006952) & $7.91 \times 10^{-18}$ \\
8. response to biotic stimulus (GO:0009607) & $1.35 \times 10^{-17}$ \\
9. response to other organism (GO:0051707) & $8.93 \times 10^{-17}$ \\
10. immune system process (GO:0002376) & 25 \\
\hline
\end{tabular}

c
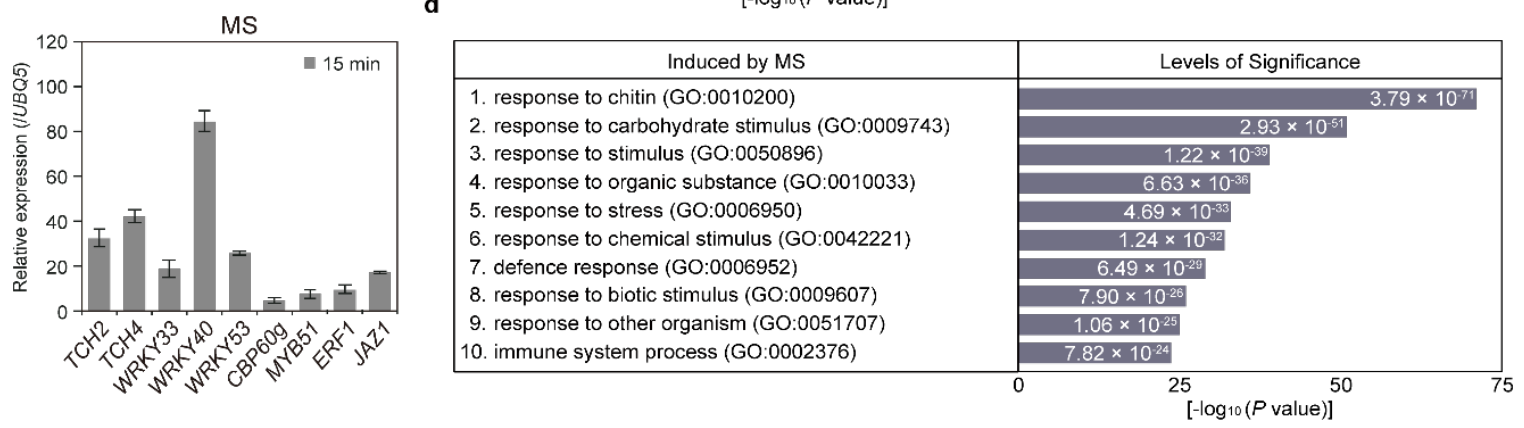

b

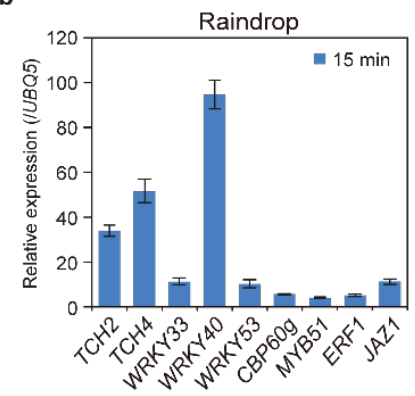

e

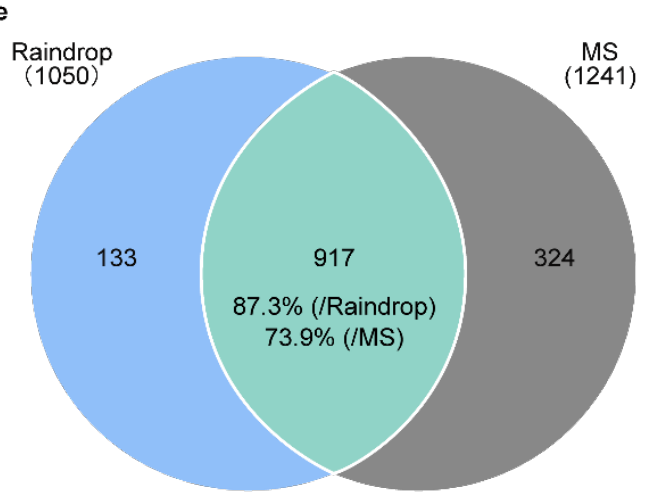

Fig. 1 | Raindrop-induced gene expression highly correlates with mechanical stimuli

f
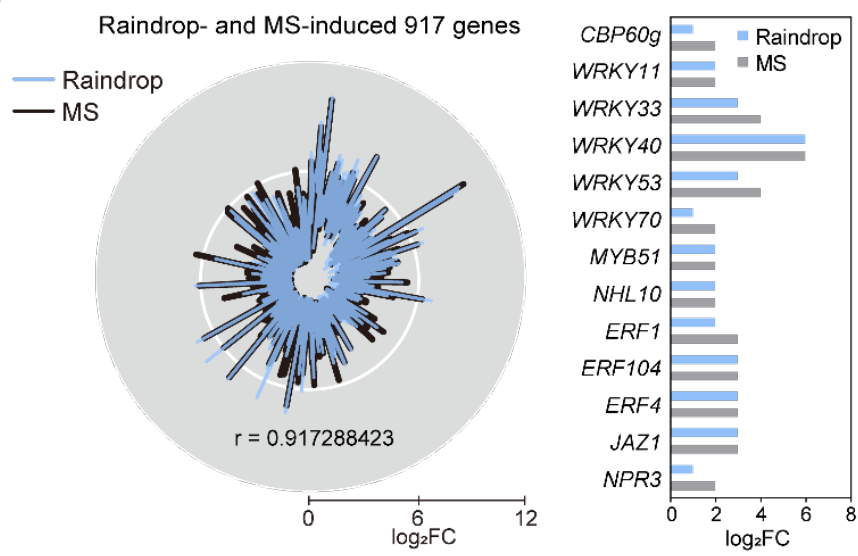
(MS)-induced gene expression in Arabidopsis. a Enriched Gene Ontology (GO) categories of 1,050 raindrop (10 droplets)-induced genes in the wild type (Col-0). The top 10 categories are shown in ascending order of $P$ values. b, $\mathbf{c}$ Transcript levels of MS-induced and defencerelated genes in 4-week-old Col-0 plants 15 min after being treated with 10 falling droplets (raindrop, b) or 1 brushing (MS, c), determined by RT-qPCR and normalized to UBIQUITIN 5 (UBQ5). Data are presented as mean \pm SD. d Enriched GO categories of 1,241 MS (1 brushing)-induced genes in Col-0. The top 10 categories are shown in ascending order of $P$ values. e Venn diagram of the overlap between transcriptome datasets from raindrop- and MS-induced genes $(P<0.05)$. f Radar chart of intensity compared with mock $\left(\log _{2} \mathrm{FC}\right)$ and 
803 Pearson correlation coefficient ( $\mathrm{r}=0.917288423)$ of 917 raindrop- and MS-induced genes

804 (left). Intensities of major immune regulator genes induced by raindrops and MS in RNA-

805 seq analysis $\left(\log _{2} \mathrm{FC}\right)($ right $)$.

806 
bioRxiv preprint doi: https://doi.org/10.1101/2021.06.13.448005; this version posted June 14, 2021. The copyright holder for this preprint (which was not certified by peer review) is the author/funder, who has granted bioRxiv a license to display the preprint in perpetuity. It is made available under aCC-BY 4.0 International license.

a

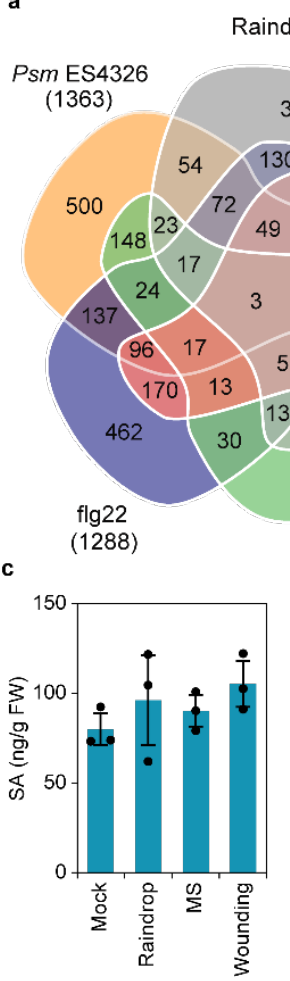

Raindrop and MS (917)
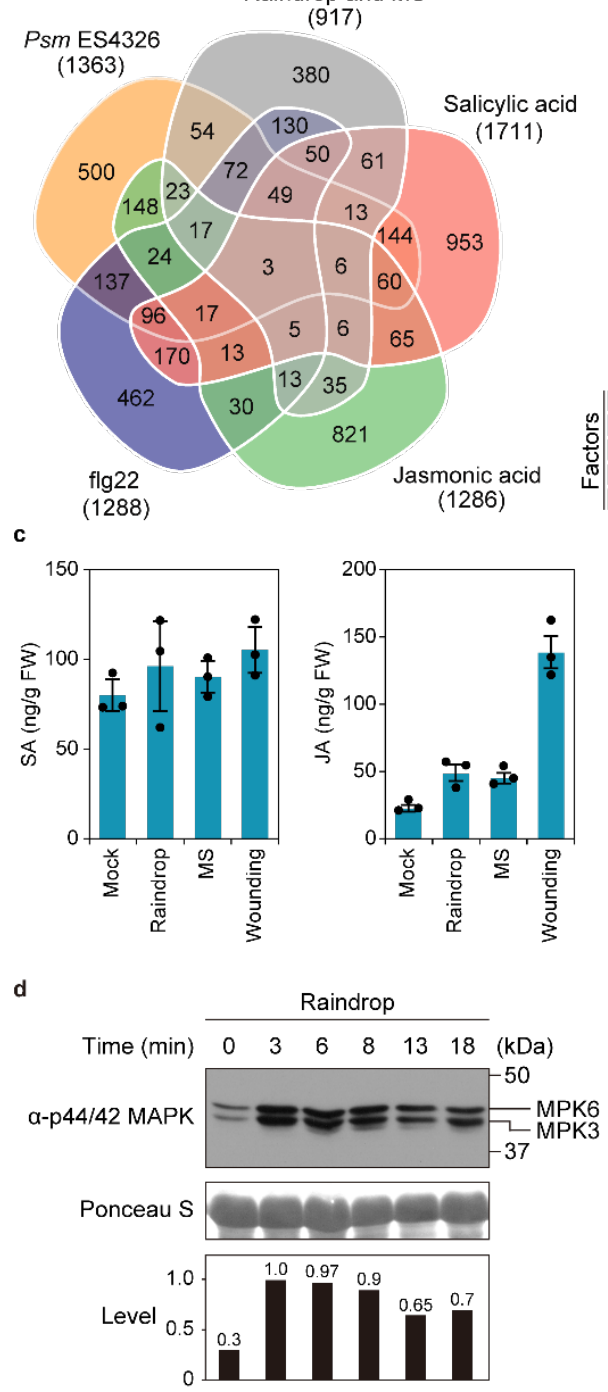

f
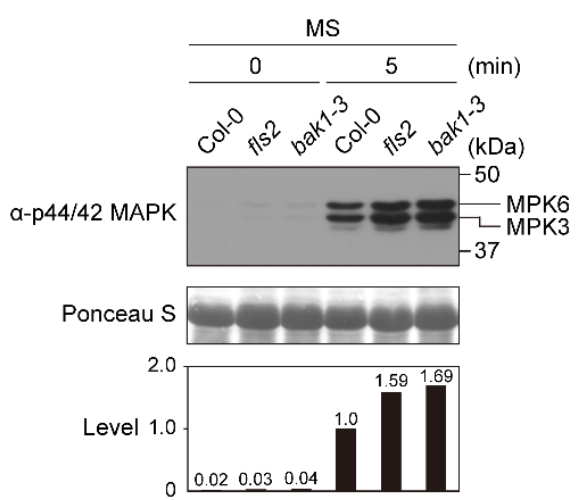

b
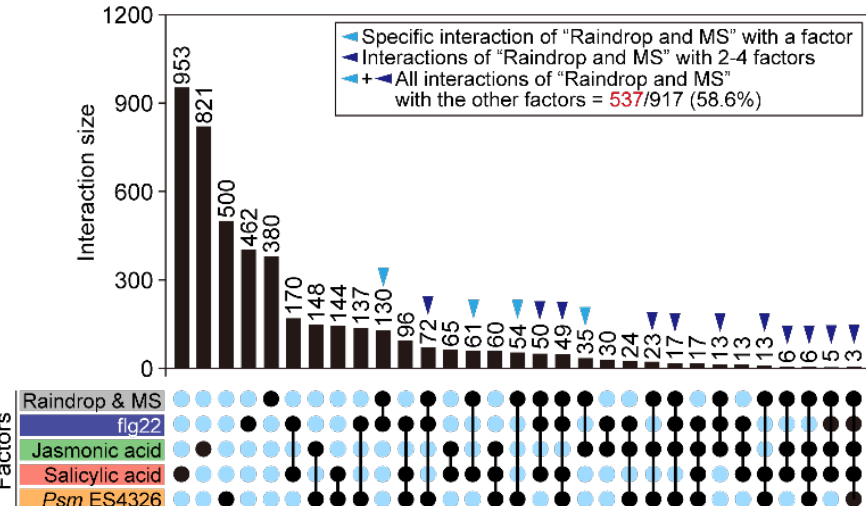

Psm ES4326
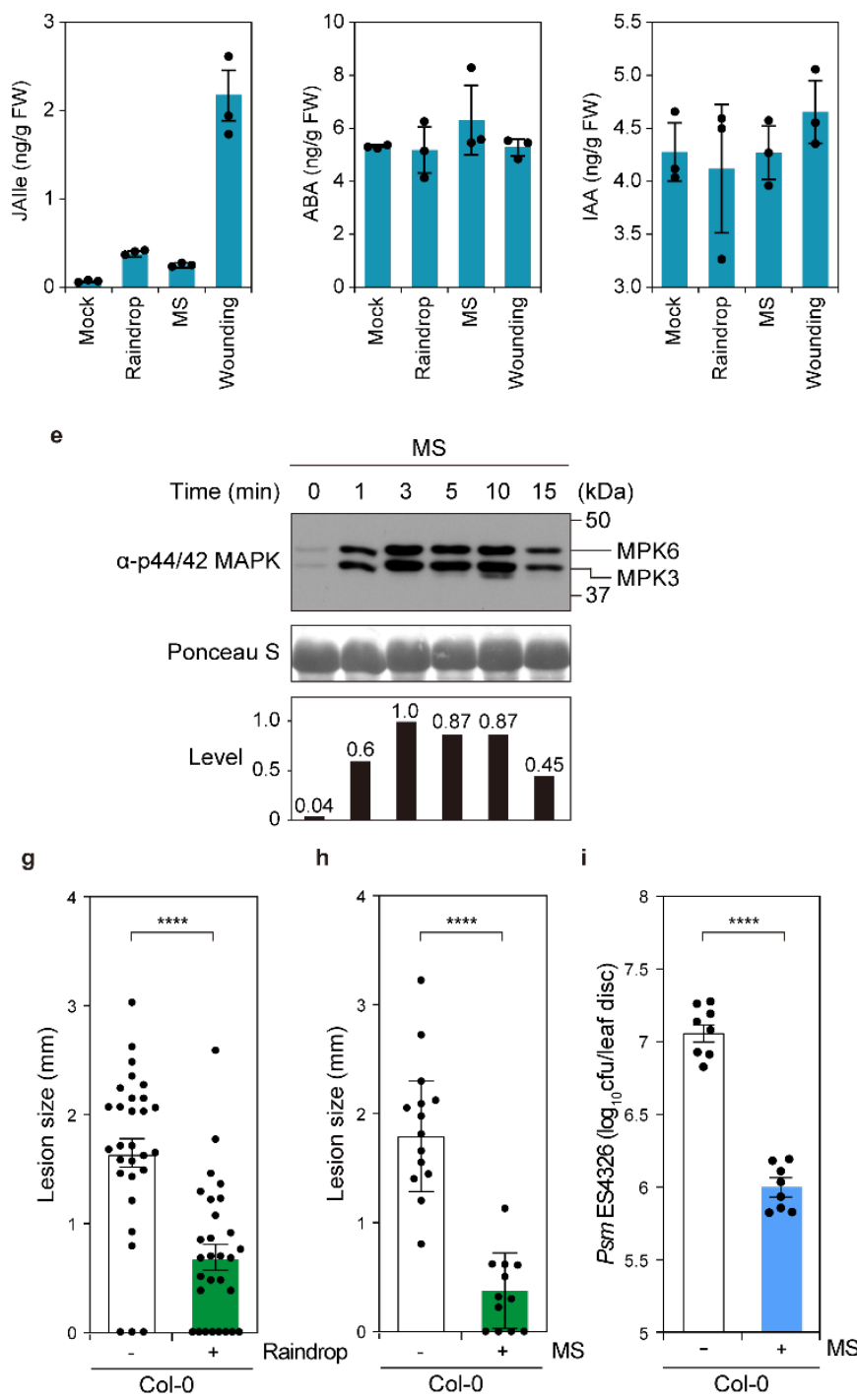
Fig. 2 | Raindrop-induced mechanosensation triggers defence responses in Arabidopsis. and transcriptome datasets obtained from salicylic acid (SA), jasmonic acid (JA), and flg22 (PAMP) treatment and Psm ES4326 infection $(P<0.05)$. Overlap with raindrop- and MSinduced genes: SA, 21\%, 193/917 genes; JA, 11.8\%, 108/917 genes; flg22, 37\%, 339/917

813 genes; Psm ES4326, 25.8\%, 237/917 genes; any of the four factors, 58.6\%, 537/917 genes.

814 c Fresh weight (ng/g) of plant hormones SA, JA, JA-isoleucine (JA-Ile), abscisic acid (ABA), 815 and indole-3-acetic acid (IAA) 5 min after 10 falling droplets (raindrop), 1 brushing (MS), 816 and cutting (wounding). d, e Raindrop (4 droplets)- (d) and MS (4 brushing)-induced (e)

817 MAPK activation in Col-0. Total proteins were extracted from 4-week-old plants treated with 818 raindrops and detected by immunoblot analysis with anti-p44/42 MAPK antibodies. Relative 819 phosphorylation levels are shown below each blot. f MS-induced MAPK activation in Col$820 \quad 0, f l s 2$, and bakl-3. Total proteins were extracted from 4-week-old plants after 5 min of MS 821 treatment (1 brushing) and detected by immunoblot analysis with anti-p44/42 MAPK 822 antibodies. Relative phosphorylation levels are shown below each blot. g, h Disease 823 progression of Alternaria brassicicola in Col-0 leaves 3 days after inoculation with $(+)$ or 824 without (-) raindrop (10 droplets) pretreatment (g) or with (+) or without (-) MS (4 brushing) 825 pretreatment (h). Error bars represent SE. Asterisks indicate significant difference (one-way 826 ANOVA; ****P<0.0001). i Growth of Psm ES4326 in Col-0 leaves 2 days after inoculation 827 with $(+)$ or without (-) MS (4 brushing) pretreatment. An outline of the experiment is 828 provided at left. Error bars represent SE. Asterisks indicates significant difference (one-way ANOVA; $* * * * P<0.0001)$. Cfu, colony-forming units. 
a

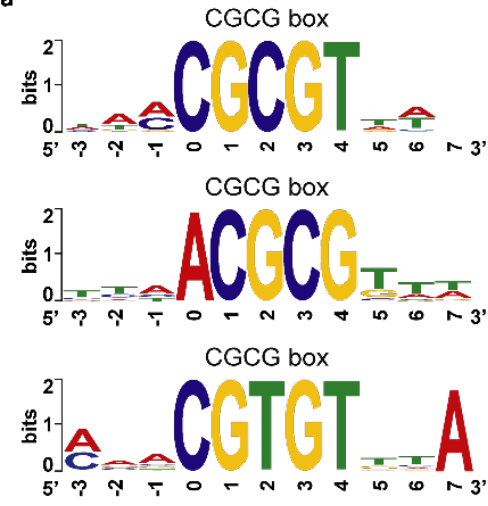

d
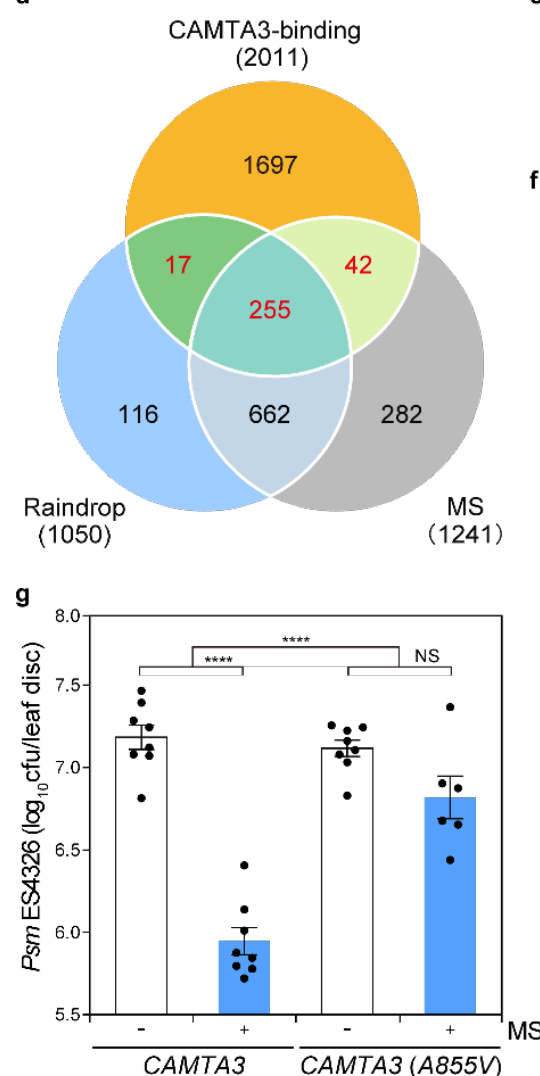
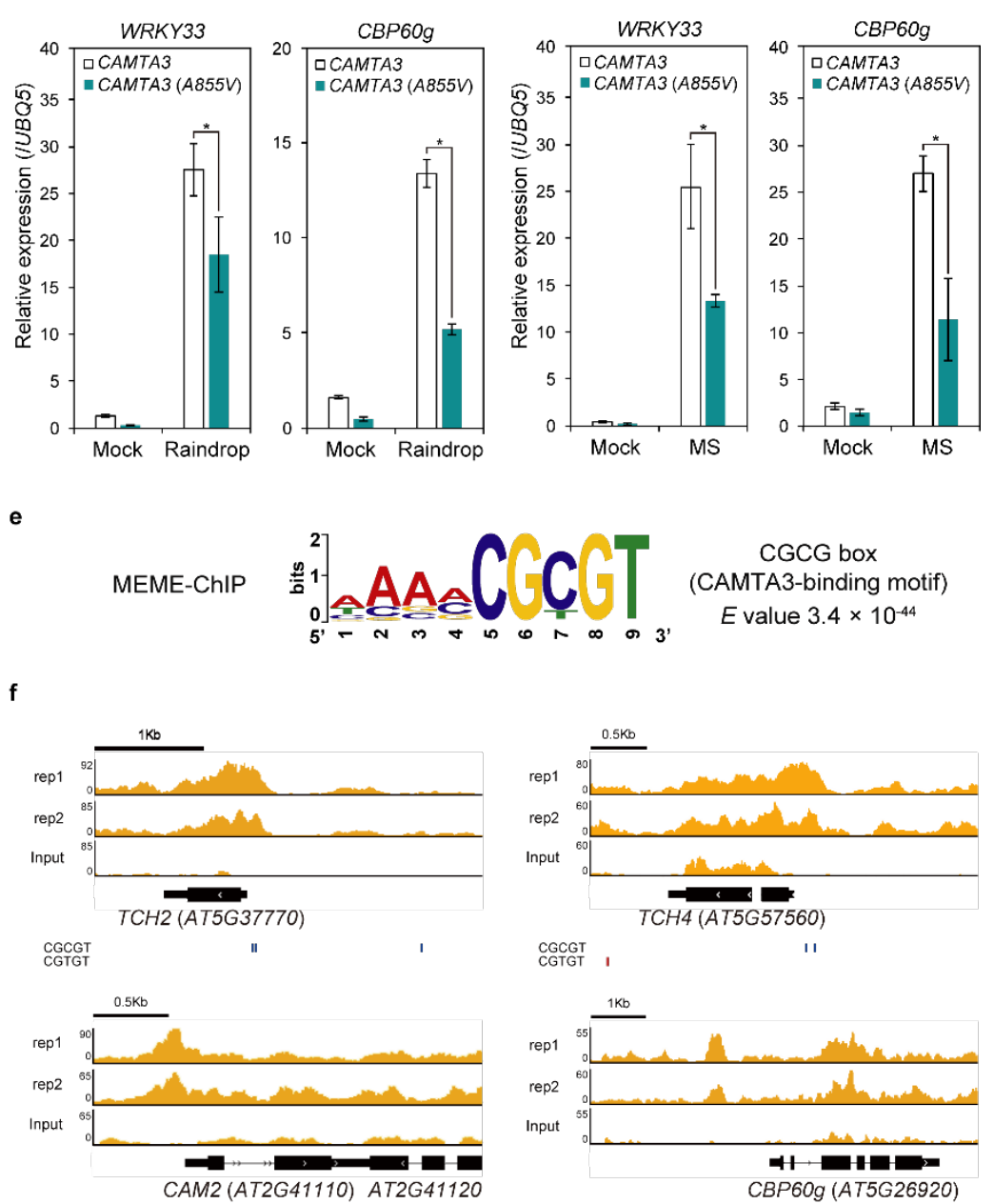
CGCGT
CGTGT

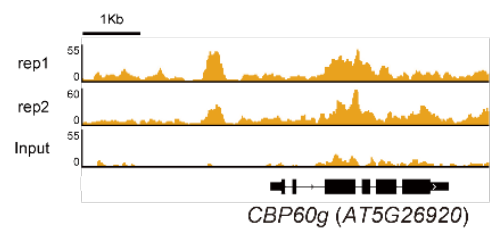
$\begin{array}{ll}\text { CGCGT } & \text { CGT }\end{array}$
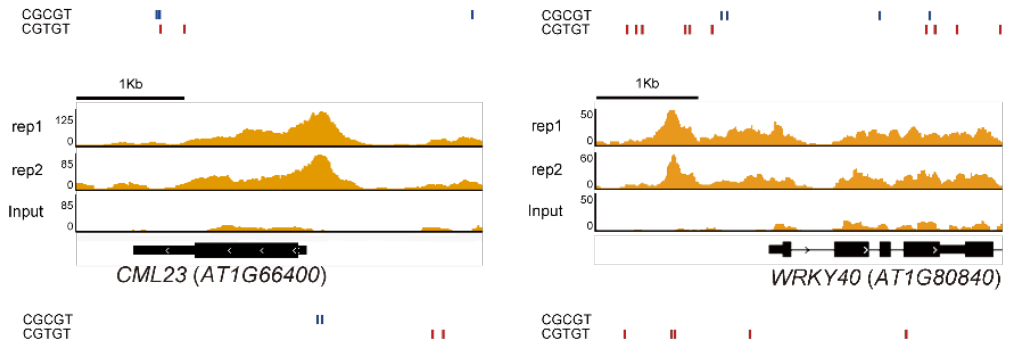

Fig. 3 | MS-induced genes are regulated by CAMTA3. a Promoter analysis of the top 300 (among 917 genes) raindrop- and MS-induced genes in terms of expression levels revealed that the CAMTA-binding CGCG box [CGC(/T)GT] were overrepresented among these genes. b, c Transcript levels of WRKY33 and CBP60g in 4-week-old camta2 camta3 CAMTA3pro:CAMTA3-GFP (CAMTA3) and camta2 camta3 CAMTA3pro:CAMTA3 ${ }^{A 855 V_{-}}$ $G F P[C A M T A 3(A 855 V)]$ plants 15 min after the plants were treated with 1 falling droplet (b) 
838 or brushed 4 times (c), determined by RT-qPCR and normalized to UBQ5 transcript levels.

839 Data are presented as mean \pm SD. d Venn diagram depicting the overlap between genes with

840 CAMTA3-binding sites in their promoters, as determined by ChIP-seq, and raindrop- and

841 MS-induced genes as determined by RNA-seq. A total of 314 genes, shown in red, were

842 identified as CAMTA3-target genes. e The CGCG box was identified as an overrepresented

843 motif among the sequence peaks of 314 genes by MEME-ChIP. f Localization of CAMTA3

844 on the promoters of the MS-induced genes TCH2, TCH4,CAM2, CBP6Og, CML23, and

845 WRKY40, as representative of the 314 genes shown in (d). Blue and red lines indicate

846 CGCGT and CGTGT, respectively. g Growth of Psm ES4326 in camta2 camta3

847 CAMTA3pro:CAMTA3-GFP (CAMTA3) and camta2 camta3 CAMTA3pro:CAMTA3 ${ }^{\text {A855V }}$

$848 G F P[C A M T A 3(A 855 \mathrm{~V})]$ plants 2 days after inoculation with $(+)$ or without (-) MS (4

849 brushing) pretreatment. Error bars represent SE. Asterisks indicate significant difference

850 (one- and two-way ANOVA; ****P<0.0001). Cfu, colony-forming units. NS, not significant. 

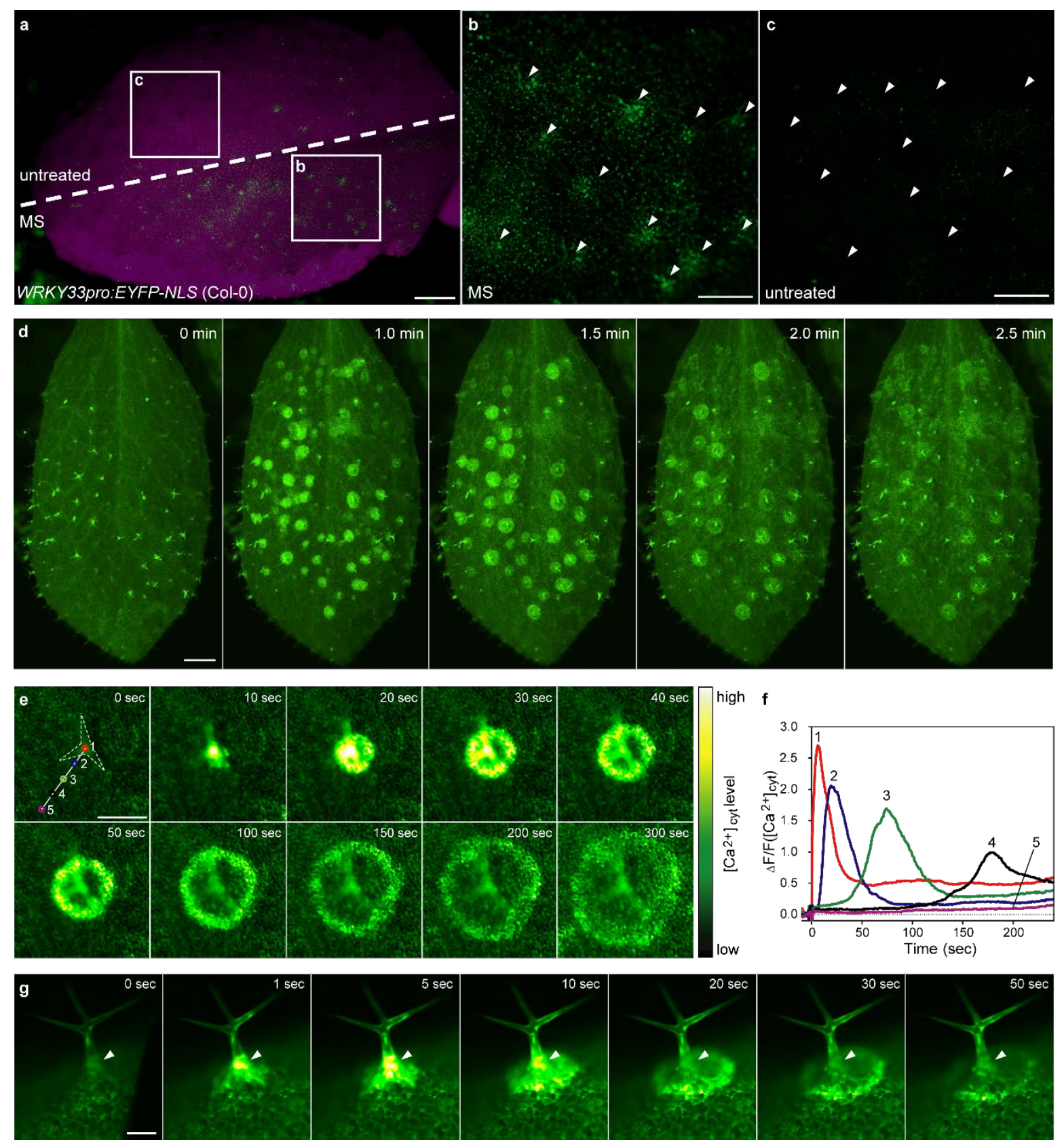

Fig. 4 | Trichomes initiate intercellular calcium waves. a-c YFP fluorescence in a whole

leaf from WRKY33pro:EYFP-NLS (Col-0) with (MS, bottom half) or without brushing

855 (untreated, top half) (a), along with zoomed-in views of brushed (b) and untreated (c) areas.

856 Arrowheads indicate trichomes $(\mathbf{b}, \mathbf{c})$. Scale bars, $0.5 \mathrm{~mm}(\mathbf{a}), 0.3 \mathrm{~mm}(\mathbf{b}, \mathbf{c}) . \mathbf{d ~ C a}{ }^{2+}$ imaging

857 using 35Spro:GCaMP3 (Col-0). The leaf surface of a 4-week-old plant was treated with MS

858 by brushing. MS-induced intercellular calcium waves propagated concentrically from 
859 trichomes. Scale bar, $1.0 \mathrm{~mm}$. See also Supplementary Video 1. e $\mathrm{Ca}^{2+}$ imaging using 860 35Spro:GCaMP3 (Col-0). A single trichome from a 2-week-old seedling was flicked with a 861 silver chloride wire. MS-induced intercellular calcium waves propagated concentrically from 862 the trichome (dashed outline). Scale bar, $0.2 \mathrm{~mm}$. See also Supplementary Video 2. f $\left[\mathrm{Ca}^{2+}\right]_{\mathrm{cyt}}$ 863 changes at sites indicated by numbers in (e). $\mathbf{g}$ Side view of a trichome whose neck was 864 flicked with a silver chloride wire. MS-induced intercellular $\mathrm{Ca}^{2+}$ influx was transiently 865 observed in the trichome base (arrowheads) followed by the formation of circular waves. 866 Scale bar, $0.1 \mathrm{~mm}$. See also Supplementary Video 3. 
a

35Spro:GCaMP3 (Col-0)

35Spro:GCaMP3 $(g / 1)$
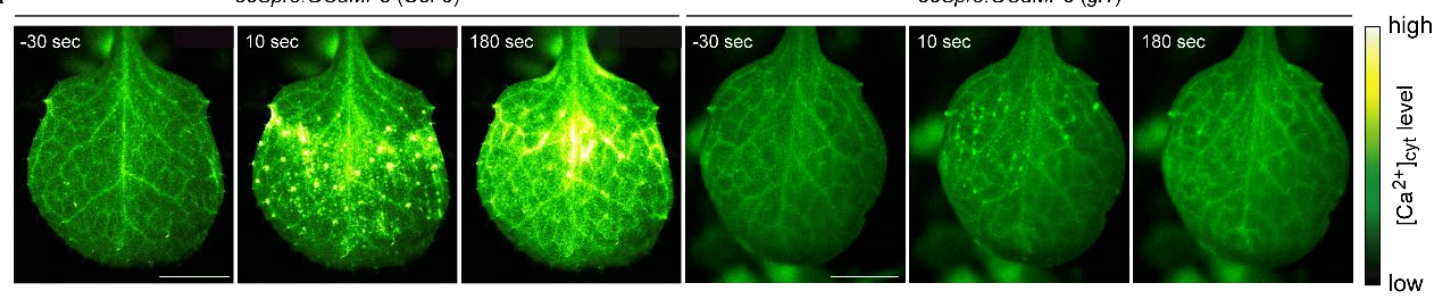

b

d
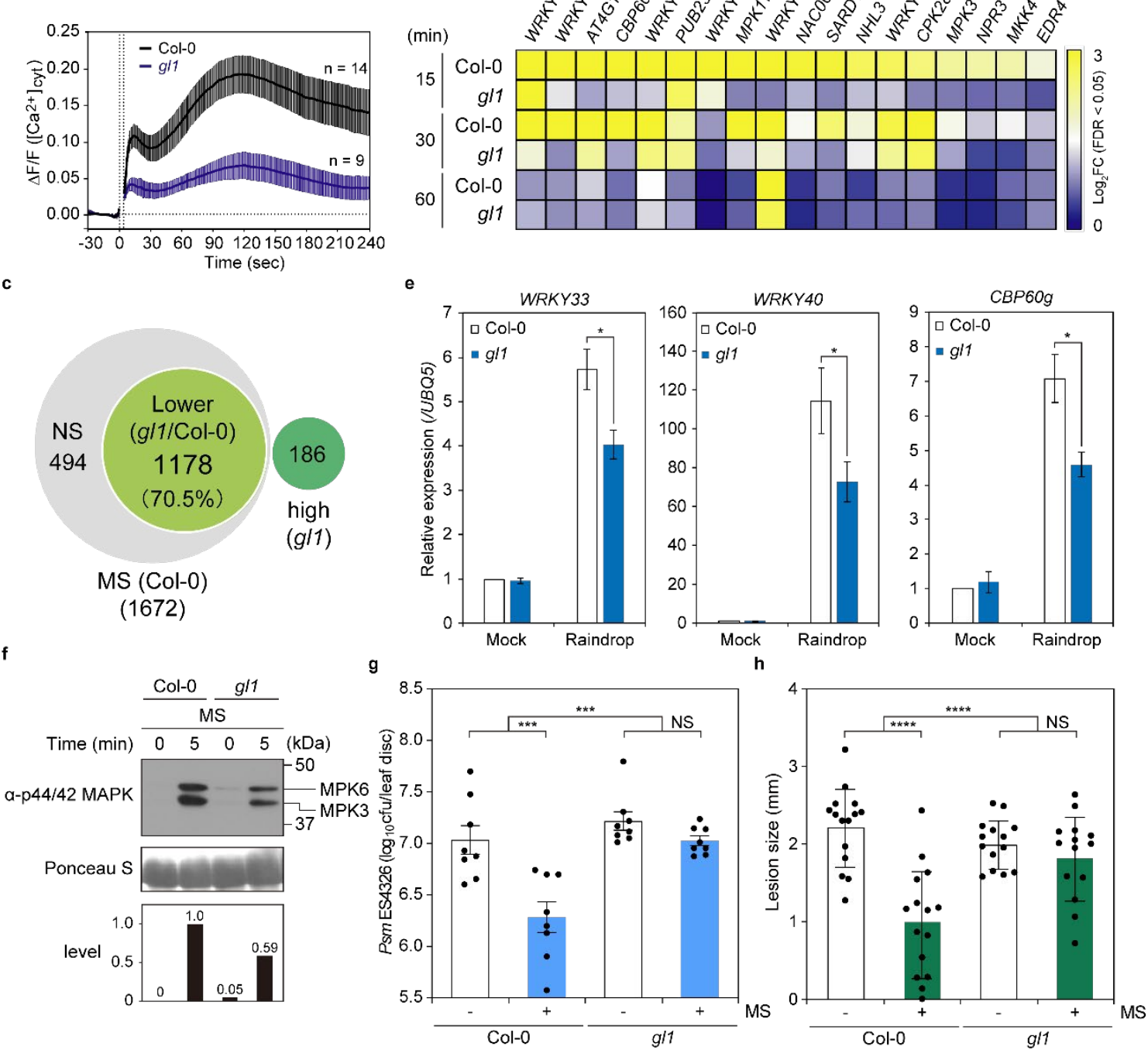

869 Fig. 5 | Trichomes are mechanosensory cells. a $\mathrm{Ca}^{2+}$ imaging using 35Spro:GCaMP3 (Col-

870 0) and 35Spro:GCaMP3 ( $\mathrm{gll}$ ). Leaf surfaces were exposed to MS by brushing. MS-induced

871 calcium waves were compromised in the gll mutant. See also Supplementary Videos 4 and

872 5. Scale bars, $0.5 \mathrm{~mm}$. b $\left[\mathrm{Ca}^{2+}\right]_{\text {cyt }}$ signature of (a). c Venn diagram of transcriptome datasets 
873 for MS-induced genes in Col-0 and $g l l(P<0.05)$. NS, not significant. Lower, fold change 874 (FC) $(g l l) / \mathrm{FC}(\mathrm{Col}-0)<0.5$. High, MS ( $g l l) /$ Mock $(g l l), \log _{2} \mathrm{FC} \geq 1$ in $g l l . P<0.05$. d 875 Heatmap of differentially expressed defence-related genes obtained from transcriptome 876 datasets from Col-0 and gll plants treated with MS (4 brushing). e Transcript levels of 877 WRKY33, WRKY40, and CBP60g in 4-week-old Col-0 and gll plants 15 min after treatment 878 with 4 falling droplets, determined using RT-qPCR and normalized to UBQ5. Data are 879 presented as mean \pm SD. Asterisks indicate significant difference (one- and two-way 880 ANOVA; $* P<0.05)$. f MS-induced MAPK activation in Col-0 and $g l l$. Total proteins were 881 extracted from 4-week-old leaves $5 \mathrm{~min}$ after MS treatment and detected by immunoblot 882 analysis with anti-p44/42 MAPK antibodies. Relative phosphorylation levels are shown 883 below each blot. g Growth of Psm ES4326 in Col-0 and gll leaves 2 days after inoculation 884 with $(+)$ or without $(-)$ MS (4 brushing) pretreatment. Error bars represent SE. Asterisks 885 indicate significant difference (one- and two-way ANOVA; $* * * P<0.001$ ). Cfu, colony886 forming units. NS, not significant. h Disease progression of Alternaria brassicicola in Col-0 887 and gll leaves 3 days after inoculation with (+) or without (-) MS (4 brushing) pretreatment. 888 Error bars represent SE. Asterisks indicate significant difference (one- and two-way ANOVA; 889 $* * * * P<0.0001)$. NS, not significant. 

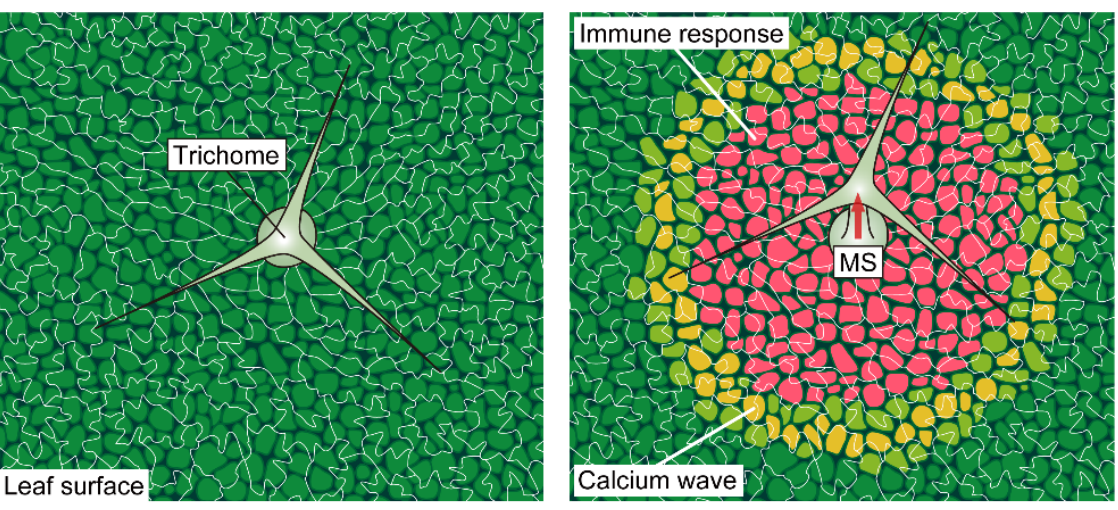

912 Fig. 6 | Trichomes activate broad-spectrum disease resistance. Model showing how

913 trichomes directly sense the mechanical impact of raindrops as an emergency signal in

914 anticipation of possible infections. Mechanosensory trichome cells initiate intercellular

915 calcium waves in response to $\mathrm{MS}$. $\left[\mathrm{Ca}^{2+}\right]_{\text {cyt }}$ initiates the de-repression of $\mathrm{Ca}^{2+} / \mathrm{CaM}-$

916 dependent CAMTA3 and activates the phosphorylation of MPK3 and MPK6, thereby

917 inducing WRKY-dependent transcription. 